\title{
Fractional order PI controller for the highly efficient power regulation of DFIG based wind power conversion system
}

\author{
Abdellatif Kasbi*, Abderrafii Rahali \\ Laboratory of Electronics, Automatics and Biotechnology, Faculty of Sciences, Moulay Ismaïl University, \\ B.P. 11201, Zitoune, Meknes, Morocco
}

\begin{abstract}
In an electric power grid connected wind generation system, dynamic control strategy is essential to use the wind energy efficiently as well as for an energy optimization. The present study has focused on decoupled power regulation of doubly fed induction generator, operating in wind turbine, in accordance with the vector control approach by applying fractional order proportional integral (FOPI) controller. The FOPI controller is designed based on a simple method; up such that the response of closed loop process is similar to the response of a specified fractional model whose transfer function is Bode's ideal function. In this tuning operation, the parameters of the proposed fractional controller are established analytically using the impulse closed-loop response of the controlled process. To show the superior action of the developed FOPI controller in comparison with standard PI controller in different function conditions, the study is validated through simulation using the software MATLAB/Simulink.
\end{abstract}

Keywords-Wind generation system, DFIG, vector control approach, fractional order PI controller, Bode's ideal transfer function, impulse response.

\section{INTRODUCTION}

$\mathrm{D}$ UE to the increasing concern about climate change, the necessity to produce pollution-free power is the need of the hour. The wind generation system is one of the best green energy sources available to meet out the energy crisis. Wind turbines exploit the kinetic power of the wind, in fact it is one of the cleanest natural energy source. Doubly fed induction generators (DFIG) are specially used in high power wind generation systems (WGSs) which is an important element of the fluctuating speed wind turbines by dint of many advantages it offers, such as the operation under variable speed, the lower converters cost, the torque control, the lower power losses, and the flexibility for active and reactive direct power control [1]-[3]. Electric grid-connected variable speed WGS considered in this study is based on a DFIG, where the stator circuit is directly connected to the electric power grid

\footnotetext{
* Corresponding author: kasbiabdellatif@gmail.com (A. Kasbi)
}

whereas the rotor circuit is connected to the electric power grid through two static power converters, which are connected back-to-back via the DC link capacitor, namely the rotor side converter (RSC) and grid side converter (GSC) [1]. During the latter few years, the development of control strategies for best operation of DFIG-generator has been the subject of intense research. The main objectives of DFIG control are to extract maximum power from the wind energy source (allows the Maximum Power Point Tracking: MPPT) protecting the different elements of the wind system and the power quality improvement which is injected into power grid [4], [5]. The modern generations of wind turbines function in variable speed mode, whose benefits include the maximum power extraction in addition, the mechanical stress mitigation [5]. Indeed, an appropriated control of back-to-back converter allows wind turbines based on DFIG-generator to operate in variable speed mode [6].

Several control approaches have been proposed in literature with promising results for studying the behavior of DFIG during operation in WGS. Mostly control schemes for DFIG are generally based on vector control concept associated with integer order proportional-integral (IOPI) controllers [7]-[10]. This approach is a very attractive solution for devices using DFIG as wind energy conversion systems; because, it is a simple practical implementation, commonly applied in the wind turbine industry and it presents very acceptable performance [11]-[14]. However, this control approach has certain limitations and has several causes. As example, its performance mainly counts on the IOPI controller design mode and the exactitude in DFIG-generator parameters and the connected electric power grid voltage conditions [15]. One of the main objectives in any realist control process is its robustness with respect to variations of its parameters and perturbations. In this context, as to weaken parametric dependence and disturbance rejection, researchers have developed different control techniques for DFIG- generator. For example, [16], [17] presented sliding mode control for the reduced parametric dependence and the disturbance rejection based on active and reactive power loops for the RSC and GSC. Indeed, the sliding mode control (SMC) strategy is rebutted against the uncertainty parameter and the external disturbance with the known upper limitations; however, the 
major bounds of this strategy include the unsuitability from the achievement point of view and the negative effect on power quality caused by high frequency chattering [16]. On the other hand, the artificial intelligence (AI) methods such as fuzzy and neural networks find numerous applications in the modern control theory. Both the fuzzy systems and artificial neural networks model are very strong schemes for the reduced parametric dependence and the disturbance rejection. They have the potential to approximate the unknown nonlinearities. Thus, both of these algorithms turn out to be a fine alternative for the control of DFIG based wind turbine system. The authors [18]-[22] developed AI algorithm established on robust control schemes for RSC control and the performance of the developed control scheme have been confirmed and the results are compared with IOPI. From the comparative study it was found that the intelligent algorithms based on controllers are more rebutted against parameter variation. In addition, these control algorithms achieve fast and robust dynamic response. However, very often they generate high frequency control signal which may augment the harmonic distortion and increase the losses in electrical winding, they produce negative effects of the quality of power supplied to electric grid.

In spite of the swift progress in control theory area, the extensively known proportional-integral-derivative (PID) controllers are very often used in the industrial application control due to the design simplicity, the practicality and the agreeable performances. As we mentioned previously, the IOPI controller has been illustrated to regulate the DFIG based on the wind turbine systems in many works. However, they suffer from the performance restrictions in cases where the process experiences the parameter uncertainty or as external disturbances. Accordingly, there is yet a lot of scope for improvement in this field.

Non-integer calculus is an extension of regular integer calculus to fractional case [23]. Recently, several researchers indicate the great interest to integrate non-integer calculus in the scheme of classical feedback control systems to obtain better performance. The concept of fractional PID controller (FOPID) was presented in 1999 by Podlubny, which proposed a generalized $P I^{\gamma} D^{\chi}$ controller whose transfer function in the Laplace domain is of the form $F(p)=k_{p}+k_{i} / p^{\gamma}+k_{d} p^{\chi}$, where $\gamma$ and $\chi$ are integrator order and differentiator order respectively [24], [25]. The remarkable characteristic of applying fractional order PID instead of integer order PID controller is due to the two supplementary parameters through tuning $\gamma$ and $\chi$ in the range [0-2] [26]. As a result, the fractional order $P I^{\gamma} D^{\chi}$ controller is qualified to provide better closed-loop performances. One of the special FOPID controllers is the FOPI controller, where $k_{d}=0$ [27].

Based on previously cited works, this paper formulates a fractional order $\mathrm{PI}^{\gamma}$ controller for the loops control of DFIGgenerator driven by the wind turbine. The design method uses the impulse response of closed loop system and requires no approximation of the installation by any mathematical model, and it is founded on a recent method proposed by [28] for design of IOPI controller, the proposed procedure uses the
Taylor-Maclaurin series of development. The three parameters of the fractional $P I^{\gamma}$ controller are tuned in a way that the closed loop system is equivalent to a specified fractional model whose closed-loop transfer function is Bode's ideal function $G_{d}(p)=1 /\left(1+\left(p / \omega_{u}\right)^{\alpha}\right)$ [29]. This type of fractional order system model is widely used in the fractional order control field, in fact it has is a very important robustness [30][34]. The developed controller is applied, in accordance with the stator flux oriented control approach, in the rotor side static converter to control the exchange of different forms of energy between the electric power grid and WGS. Indeed, the control loops of RSC are created to regulate the stator active power, such that the WGS operates at the optimal operating point with use of MPPT control strategy during the variation in environmental conditions; while the stator reactive power is controlled so as to reduce the DFIG-windings Joule losses. With the designed FOPI controller in this paper, the servo and regulatory responses through simulations for normal operating conditions as well as where the process experiences as external disturbances are obtained and analyzed. The proposed controllers realize the fastest dynamic and assist us in incorporating a higher level of robustness without stressing the static converters or deteriorating the power quality injected in to electric power grid.

The rest of the paper is arranged as follows: The dynamic models of the wind turbine system and DFIG-generator are formulated in Section II. Section III presents details of the DFIG based variable speed WGS control strategy. Section IV is a brief presenting of the basic of given fractional calculus. Section V describes details of the developed fractional order $P I^{\gamma}$ controller design technique. The fractional order $P I^{\gamma}$ controller synthesis and implementation for control DFIGgenerator based WGS are given in Section VI. In Section VII, the variable speed WGS with the proposed controller is simulated via MATLAB/Simulink software and the performances of controller are evaluated under different operating conditions. Furthermore, the results obtained are analyzed and discussed in this section. Finally, the concluding statements of the paper are given in Section VIII.

\section{VARIABLE SPEED WGS MODEL}

Fig. 1 describes the topology under consideration in this work of electric power grid connected DFIG based variable speed WGS. The wind energy is captured by the turbine and transmitted through the latter to the three-phase DFIG and generated in electrical form. From the block diagram, it is noted that DFIG-generator is fundamentally a wound-rotor induction machine with stator windings is directly connected to the electric power grid, while the rotor windings is connected to the grid through a power stage consisting of two independent static converters connected to a common DC bus, namely GSC and GSC.

\section{A. Modeling of Wind Turbine}

The fraction of the extracted power from wind is expressed by [22]: 


$$
P_{\text {extracted }}=0.5 \rho_{\text {air }} S C_{p}(\lambda, \beta) v^{3}
$$

where $\rho_{\text {air }}$ is the air density, $S$ is the turbine area, $C_{p}$ is the

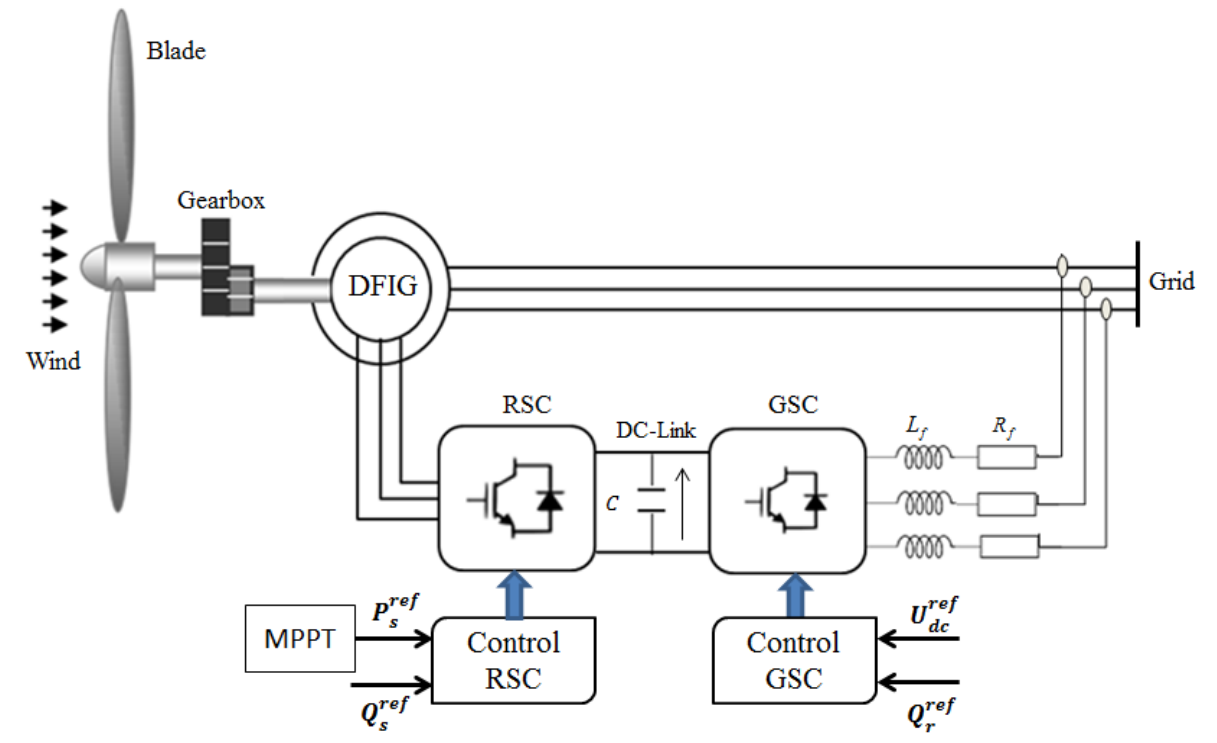

Fig. 1 Configuration of wind turbine based on DFIG

$$
\lambda=\Omega_{t} R / v
$$

where $\Omega_{t}$ the turbine angular shaft speed and $R$ is the turbine radius.

The aerodynamic torque exerted on the slow shaft of the turbine is expressed as:

$$
C_{t}=P_{\text {extacted }} / \Omega_{t}=0.5 \rho_{\text {air }} \pi R^{3} v^{2} C_{p}(\lambda, \beta) / \lambda
$$

The gear box adapts the speed of the turbine to the speed of the generator; it is modeled by the following mathematical relations:

$$
C_{g}=C_{t} / G \quad \text { And } \quad \Omega_{t}=\Omega_{m} / G
$$

The following equation models the fast shaft of the turbine:

$$
J \frac{d \Omega_{m}}{d t}=C_{m}=C_{g}-C_{e m}-f_{v i s} \Omega_{m}
$$

where J: Total inertia that appears on the shaft of the generator, $C_{m}$ : Total mechanical torque on the axis of the generator, $C_{g}$ : Torque from the Gear Box, $C_{e m}$ : Torque electromagnetic produced by the DFIG-generator, $f_{\text {vis }}$ : Viscous friction coefficient, $\Omega_{m}$ : Mechanical angular speed of the generator.

A generic expression of power coefficient $C_{p}(\lambda, \beta)$ is used in [35], [36], this typical characteristic of the turbine is given by:

$C_{p}(\lambda, \beta)=0.5176\left(\frac{116}{\lambda_{i}}-0.4 \beta-5\right) \exp \left(\frac{21}{\lambda_{i}}\right)+0.0068 \lambda(6)$

where $\lambda_{i}$ is given by the following equality: power coefficient which depends on the pitch angle $\beta$ and tip speed ratio (TSR) $\lambda$ and $v$ is the wind speed.

$$
\frac{1}{\lambda_{i}}=\frac{1}{\lambda+0.08 \beta}-\frac{0.035}{\beta^{3}+1}
$$

Fig. 2 shows the amplitude of the power coefficient in function of the parameters $\lambda$ and $\beta$. This curve is characterized an optimum point: for the pitch angle $\beta=0^{\circ}$, it has a unique maximum point of $\mathrm{C}_{\text {pmax }}=0.48$ at $\lambda_{\text {opt }}=8.1$; this value represents the Betz limit, which is the point corresponding to the maximum power coefficient $\mathrm{C}_{\mathrm{p}}$ and consequently, the most mechanical power can be extracted by the wind turbine. So as to conserve $\lambda$ at its optimum value and consequently, maximize the captured power, it is necessary to vary the rotation speed of the turbine in a linear manner with the wind speed pursuant to (2).

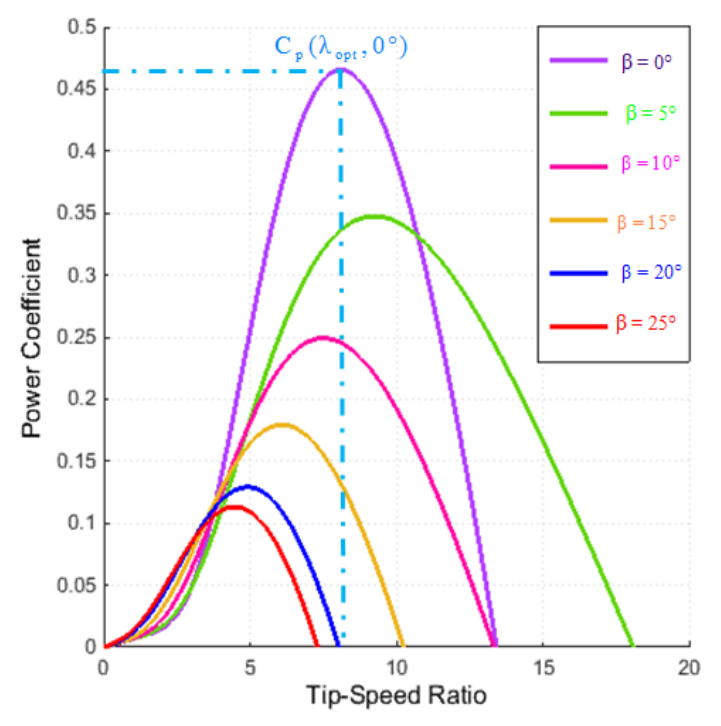

Fig. 2 Power coefficient curve of a variable-pitch wind turbine 


\section{B. MPPT Control Strategy}

If the pitch angle $\beta$ is a constant (such as zero degrees), an optimal TSR ( $\lambda_{\text {opt }}=8.1$ ) can be found that is corresponding to the maximum power coefficient $\left(C_{p_{-} \max }=0.48\right)$. The aerodynamic power as a function of generator speed, for different wind speeds and blade pitch angle $\beta=0^{\circ}$, is illustrated in Fig. 3.

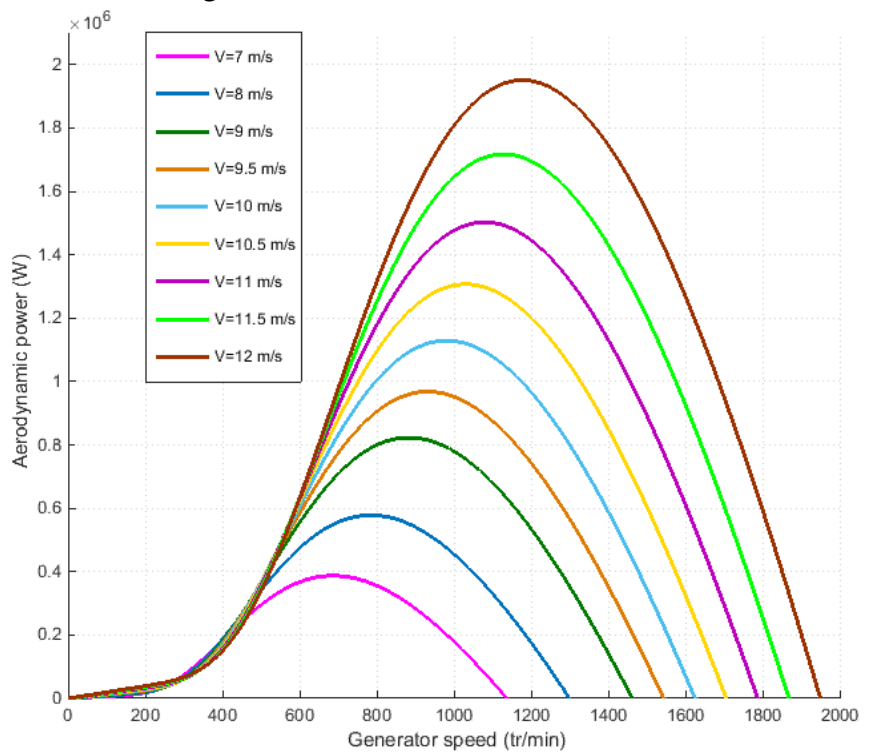

Fig. 3 Aerodynamic power characteristics (Pitch angle $\beta=0^{\circ}$ )

WGS principle can be considered as a relatively straight forward process. This process becomes much more involved when we apply a control in order to capture the maximum energy from the wind. By exploiting Fig. 3, it can be observed that the maximum point of the power curve occurs at a particular rotor speed for each wind speed. Therefore, a small deviation from the optimum rotor speed can lead a significant decrease in the output power of the wind turbine. Therefore, the turbine rotational speed must be adjusted with a view all the time to extract the maximum power of incident energy of it [36], [37]. The optimal mechanical turbine speed corresponds has $\lambda_{\text {opt }}$ and $\beta=0^{\circ}$; and the corresponding rotor speed of DFIG generator is applied as the desired value for a proportional-integral controller. The output signal of the latter determines the control signal which is the electromagnetic torque that should be exercised to the machine to operate at its optimal speed. Thus, the torque determined by the controller is used as a reference torque of the turbine model, as shown in Fig. 4. From the relation $\lambda=\Omega_{\mathrm{t}} \cdot \mathrm{R} / \mathrm{v}$, the mechanical power is maximal if the maximum value of coefficient $C_{p}$ is reached.

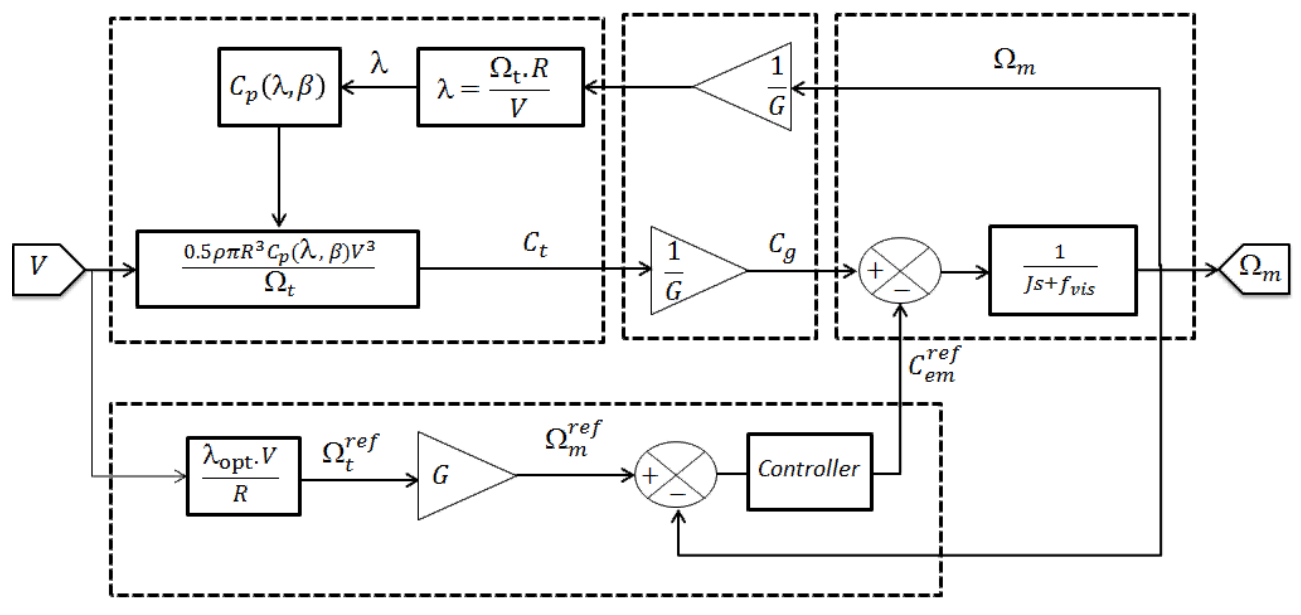

Fig. 4 MPPT control strategy

\section{Dynamic Model of DFIG}

In this work, DFIG control is done out through the static RSC, which is connected with the GSC in back-to-back mode via the common DC bus as shown in the synoptic diagram of the WGS based on the DFIG in Fig. 1. So as to efficiently control the DFIG, we present in preferred way the dynamics electrical model of the DFIG-generator in a synchronous reference frame $(\mathrm{d}, \mathrm{q})$ rotating at an angular speed of $\omega_{s}$. According to [38]-[40], the basic equations used to model the DFIG-generators in the rotating $\mathrm{d}-\mathrm{q}$ reference frame are written as:

$$
\begin{gathered}
\left\{\begin{array}{c}
V_{s d}=R_{s} I_{s d}+\frac{d \varphi_{s d}}{d t}-\omega_{s} \varphi_{s q} \\
V_{s q}=R_{s} I_{s q}+\frac{d \varphi_{s q}}{d t}+\omega_{s} \varphi_{s d} \\
V_{r d}=R_{r} I_{r d}+\frac{d \varphi_{r d}}{d t}-\left(\omega_{s}-\omega\right) \varphi_{r q} \\
V_{r q}=R_{r} I_{r q}+\frac{d \varphi_{r q}}{d t}+\left(\omega_{s}-\omega\right) \varphi_{r d}
\end{array}\right. \\
\left\{\begin{array}{l}
\varphi_{s d}=\mathrm{L}_{s} \mathrm{I}_{\mathrm{sd}}+\mathrm{L}_{\mathrm{m}} \mathrm{I}_{\mathrm{rd}} \\
\varphi_{\mathrm{sq}}=\mathrm{L}_{\mathrm{s}} \mathrm{I}_{\mathrm{sq}}+\mathrm{L}_{\mathrm{m}} \mathrm{I}_{\mathrm{rq}} \\
\varphi_{\mathrm{rd}}=\mathrm{L}_{\mathrm{m}} \mathrm{I}_{\mathrm{sd}}+\mathrm{L}_{\mathrm{r}} \mathrm{I}_{\mathrm{rd}} \\
\varphi_{\mathrm{rq}}=\mathrm{L}_{\mathrm{m}} \mathrm{I}_{\mathrm{sq}}+\mathrm{L}_{\mathrm{r}} \mathrm{I}_{\mathrm{rq}}
\end{array}\right.
\end{gathered}
$$

$\omega=P \Omega_{m}$ 
with P: number of pole pairs of the DFIG; $\left(V_{s, r d}, V_{s, r q}\right)$ are the stator and rotor voltages in reference frame $(d, q)$; $\left(I_{s, r d}, I_{s, r q}\right)$ are direct and quadrature currents of the stator and rotor; $\left(\varphi_{s, r d}, \varphi_{s, r q}\right)$ are the stator and rotor flux in reference frame $(\mathrm{d}, \mathrm{q}) ; R_{s}, R_{r}$ are the stator and rotor resistances; $L_{s}, L_{r}, L_{m}$ are stator inductance, rotor inductance, and mutual inductance; $\omega_{s}, \omega$ are the stator and rotor angular velocities, respectively.

The active and reactive power expressions of stator and rotor of the DFIG are written as follows [20], [35], [41]:

$$
\left\{\begin{array}{l}
P_{s}=\left(V_{s d} I_{s d}+V_{s q} I_{s q}\right) \\
Q_{s}=\left(V_{s q} I_{s d}-V_{s d} I_{s q}\right) \\
P_{r}=\left(V_{r d} I_{r d}+V_{r q} I_{r q}\right) \\
Q_{r}=\left(V_{r q} I_{r d}-V_{r d} I_{r q}\right)
\end{array}\right.
$$

\section{WGS CONTROL STRATEGY}

\section{THE DOUBLY EXCITED MACHINES ARE} INTRINSICALLY QUALIFIED OF hyper-synchronous speed operating. To assure operation in the $\pm 30 \%$ speed range around the synchronism speed, the secret lies the power converters technology. In the hyper-synchronous operating mode $\left(\omega>\omega_{s}\right)$, the power flows from the rotor circuit to electric power grid through the static converters, while the power flows from electric power grid to rotor circuit when the generator operates in hypo-synchronous mode $\left(\omega<\omega_{s}\right)$. Accordingly, the cascade back to back static converters allow bidirectional transfer of rotor power. The active and reactive power generated by generator can be controlled independently because of the static converters connected to the electric circuit of the rotor. Indeed, the control loops of RSC controls the generated active power so that the WGS operates at the optimum operating point using MPPT control during varying environmental conditions; the same converter controls the stator reactive power whose objective is to reduce the Joule losses in the DFIG- generator.

The purpose of this section is to present the control mechanism of control loops RSC whose the main task is to control DFIG generated active and reactive power. Indeed, we propose a control scheme whose architecture composed the outer-loop to power control and the inner-loop to current control for each axis d and q, as depicted in Fig. 5. The loopscontrol of the RSC is prepared according to the vector control approach [38] for hypothetical perpendicular $\mathrm{d}$ and $\mathrm{q}$ axes.

Based on vector control approach, the active and reactive power injected in to electric power grid can be separately controlled. If the stator flux is oriented along to the d-axis of the $d-q$ reference frame, we have:

$$
\varphi_{s d}=\varphi_{s} \text { and } \varphi_{s q}=0
$$

If the per phase stator resistance is neglected, which is a realistic and acceptable approximation for medium power machines, the direct and quadrature stator voltages become:

$$
\left\{\begin{aligned}
V_{s d} & =0 \\
V_{s q}=V_{s} & =\omega_{s} \varphi_{s}
\end{aligned}\right.
$$

Using (11) and (12) in (7) and (10) the rotor voltages, the stator currents and the stator active and reactive power can be expressed according to the rotor currents as follows:

$$
\begin{aligned}
& \left\{\begin{array}{c}
V_{r d}=R_{s} I_{r d}+\sigma L_{r} \frac{d I_{r d}}{d t}-\sigma L_{r} g \omega_{s} I_{r q} \\
V_{r q}=R_{s} I_{r q}+\sigma L_{r} \frac{d I_{r q}}{d t}+\sigma L_{r} g \omega_{s} I_{r d}+g \frac{L_{m} V_{s}}{L_{s}}
\end{array}\right. \\
& \left\{\begin{array}{c}
I_{s d}=-\frac{L_{m}}{L_{s}} I_{r d}+\frac{\varphi_{s}}{L_{s}} \\
I_{s q}=-\frac{L_{m}}{L_{s}} I_{r q}
\end{array}\right. \\
& \left\{\begin{array}{c}
P_{s}=-\frac{V_{s} L_{m}}{L_{s}} I_{r q} \\
Q_{s}=-\frac{V_{s} L_{m}}{L_{s}} I_{r d}+\frac{V_{s} \varphi_{s}}{L_{s}}
\end{array}\right.
\end{aligned}
$$

With $\sigma=1-\frac{L_{m}^{2}}{L_{s} L_{r}}$ : the dispersion coefficient of the DFIG; $g=\frac{\omega_{s}-\omega}{\omega_{s}}:$ the slip rang.

It is well known that MPPT control strategy improved energy efficiency of WGS and consequently improved active power generated. In this paper, we propose another improvement possible concerning this time the reactive power control. Indeed, the stator reactive power is controlled to protect windings against the aging phenomenon, that is to say it is controlled to reduce of generator copper losses.

Generator copper losses can be expressed as:

$$
P_{C u}=\left(I_{s d}^{2}+I_{s q}^{2}\right) R_{s}+\left(I_{r d}^{2}+I_{r q}^{2}\right) R_{r}
$$

Substituting the expressions of $I_{s d}$ and $I_{s q}$ in (16), we get:

$$
P_{C u}=\left(R_{r}+\frac{L_{m}^{2}}{L_{s}^{2}} R_{s}\right) I_{r d}^{2}+\frac{\varphi_{s}^{2}}{L_{s}^{2}} R_{s}-\frac{2 L_{m} \varphi_{s} R_{s}}{L_{s}^{2}} I_{r d}+\left(R_{r}+\frac{L_{m}^{2}}{L_{s}^{2}} R_{s}\right) I_{r q}^{2}
$$

In (15), $I_{r q}$ has been used to control stator active power, and $\varphi_{s}$ remains approximately constant as described above, then the generator copper loss is a function of direct rotor current $I_{r d}$. For the copper loss to be minimal, it is necessary that:

$$
I_{r d}=\frac{L_{m} \varphi_{s} R_{S}}{L_{s}^{2} R_{r}+L_{m}^{2} R_{s}}
$$

By substituting the expression of direct rotor current $I_{r d}$ in (15), we get the expression of reactive power optimal exchanged between the stator of DFIG-generator and grid as:

$$
Q_{S-o p t}=Q_{s}^{r e f}=-\frac{V_{S} L_{m}}{L_{S}}\left(\frac{L_{m} \varphi_{S} R_{S}}{L_{S}^{2} R_{r}+L_{m}^{2} R_{S}}\right)+\frac{V_{s} \varphi_{s}}{L_{S}}
$$

As we explained in Section II $B$, the power captured through turbine from the wind is maximized if the machine 
speed is adapted such that the power coefficient is maximum $\left(C_{p}=C_{p_{-} \max }\right)$, which occurs for a determined tip speed ratio $\left(\lambda_{\text {opt }}\right)$. The DFIG control aims to keep the machine speed in its optimum value and hence, to maximize the produced power in a vast range of wind speeds, according to the following expression:

$$
\Omega_{\mathrm{m}}^{\mathrm{ref}}=G \frac{\lambda_{\mathrm{opt}} \mathrm{V}}{\mathrm{R}}
$$

Therefore, the stator active power reference injected to the electric power grid can be obtained as:

$$
P_{s}^{r e f}=P_{o p t}=\frac{0.5 \rho_{\text {air }} \pi R^{5} C_{p-\max }}{\lambda_{o p t}^{3}} \Omega_{\mathrm{m}}^{3}
$$

where $P_{\text {opt }}$ is the optimal power that can be captured from the wind.

Based on the control strategy discussed above, Fig. 5 shows an implementation of the control of the RSC.

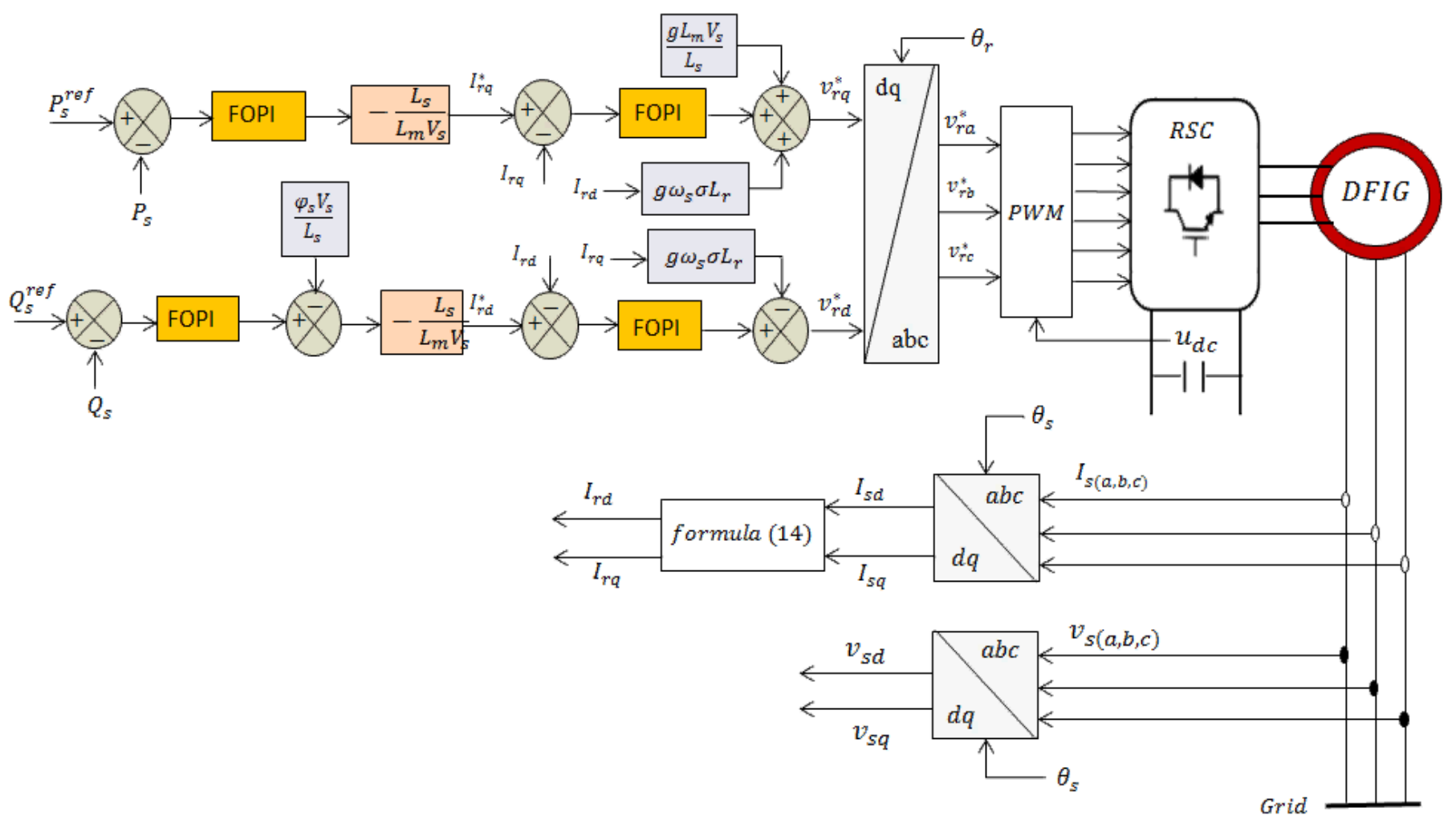

Fig. 5 Implementation of RSC control system

\section{EsSential Definitions for Fractional CAlCulus}

Non-integer order derivatives and integrals are generalizations of the integer order ones. Fractional order basic operators are frequently represented as ${ }_{a} D_{t}^{m}$ where $a$ and $t$ are the boundaries and $m(m \in \mathfrak{R})$ the operation order. The continuous differential-integral operator is described as [33], [42]:

$$
{ }_{a} D_{t}^{m}= \begin{cases}\frac{d^{m}}{d t^{m}} & m>0 \\ 1 & m=0 \\ \int_{a}^{t}(d \tau)^{m} & m>0\end{cases}
$$

The researches in such an imprecise subject drove mathematicians to numerous separate definitions of this operator. Riemann Liouville's definition is one of the most popular fractional integer-differential operator definitions for fractional calculus; the fractional order Riemann-Liouville integration and derivative of a function $f(t)$ with $t$ respect to is expressed by [32], [42]-[44]:

$$
\begin{aligned}
& { }_{a} D_{t}^{-m} f(t)=\frac{1}{\Gamma(-\mathrm{m})} \frac{d^{n}}{d t^{n}} \int_{a}^{t}(t-\tau)^{-m-1} f(\tau) d \tau \\
& { }_{a} D_{t}^{m} f(t)=\frac{1}{\Gamma(\mathrm{n}-\mathrm{m})} \frac{d^{n}}{d t^{n}} \int_{a}^{t}(t-\tau)^{-m+n-1} f(\tau) d \tau
\end{aligned}
$$

In (24) $\mathrm{n} \in \mathrm{N}, \mathrm{n}-1<m<n$ and $\Gamma($.) denotes the Euler's Gamma function which is expressed as:

$$
\Gamma(z)=\int_{0}^{+\infty} e^{-t} t^{z-1} d t \quad z>0
$$

The Laplace transform of the Riemann-Liouville noninteger operator for the $m(0<m<1)$ and under null initial conditions is determined by [44]:

$$
L\left\{{ }_{a} D_{t}^{ \pm m} f(t)\right\}=s^{ \pm m} F(s)
$$

So as to implement this FOPI controller, we are employing the singularity function approximation of the non-integer order system developed in 1992 by [45]. 
In Laplace domain, the transfer function of non-integer order integral operator is described to the next irrational function:

$$
H(s)=\frac{1}{s^{m}} \quad m \in[0,1]
$$

This fractional order operator, in a given frequency interval, can be represented through a fractional power pole (FPP) as:

$$
H(s) \approx \frac{\left(1 / \omega_{c}\right)^{m}}{\left(1+\omega / \omega_{c}\right)^{m}}
$$

In accordance with Charef et al., [45] in a given frequency band $\left[\omega_{b}, \omega_{h}\right],(28)$ becomes:

$$
\begin{aligned}
& H(s)=\left(1 / \omega_{c}\right)^{m} \times \frac{\prod_{i=0}^{N-1}\left(1+\frac{s}{z_{i}}\right)}{\prod_{i=0}^{N}\left(1+\frac{s}{p_{i}}\right)} \\
& \omega_{c}=\omega_{b} \sqrt{10^{\left(\frac{y}{10 m}-1\right)}}
\end{aligned}
$$

$y$ : The maximum difference allowed between the slopes of the FPP of (28) and the frequency response of the operator of (27). On the other hand, the zeros and poles of the singularity function can be expressed as:

$$
\begin{aligned}
& p_{i}=p_{0}(a b)^{i} \text { for } i=0,1,2,3, \ldots, N \\
& z_{i}=z_{0}(a b)^{i} \text { for } i=0,1,2,3, \ldots, N-1 \\
& p_{0}=\omega_{c} b^{1 / 2}, z_{0}=a p_{0}, a=10^{\left(\frac{y}{10(1-m)}\right)}, b=10^{\left(\frac{y}{10 m}\right)}
\end{aligned}
$$

The number of approximation poles $\mathrm{N}$ is:

$$
N=\text { integer }\left\{\frac{\log \left(\frac{\omega_{\max }}{p_{0}}\right)}{\log (a b)}\right\}
$$

\section{V.DESIGN OF PROPOSED FRACTIONAL ORDER PI ${ }^{\Gamma}$ CONTROLLER}

In this section, a simple method is presented for designing the fractional order $\mathrm{PI}^{\gamma}$ controller in order to apply it in control loops RSC. The considered design method is drawn up in a way that the closed loop process is equivalent to a specific fractional order model whose transfer function is Bode's ideal function. In this method, the characteristic parameters of the designed $P I^{\gamma}$ controller are established analytically using the impulse response of the process and without needs its model.

The simplified control scheme of control loops of rotor side static converter is shown in Fig. 6, where $G_{p}(s)$ represents the open-loop transfer function of controlled process, $\mathrm{C}(\mathrm{s})$ represents the $\mathrm{PI}^{\gamma}$ controller, and the set-point, the measured output, the control signal at time $\mathrm{t}$ and the error signal are denoted $\operatorname{as~}^{*}(\mathrm{t}), \mathrm{Y}(\mathrm{t}), \quad u(t)$ and $\varepsilon(\mathrm{t}), \quad$ respectively. The controller $C(s)$ is a fractional order $P I^{\gamma}$ controller whose transfer function is described as follows:

$$
C(s)=k_{p}+\frac{k_{i}}{s^{\gamma}}
$$

where $k_{p}$ is the proportional action, $k_{i}$ is the integral action and $\gamma$ is the fractional order. Design the $P I^{\gamma}$ controller consists of determining its three characteristic parameters $k_{p}, k_{i}$ and $\gamma$. We consider the diagram of the feedback control process shown in Fig. 6, the corresponding closed-loop transfer function is given by:

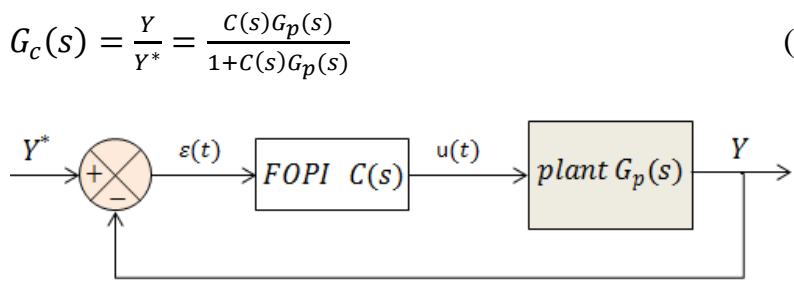

Fig. 6 Feedback control loop with FOPI controller

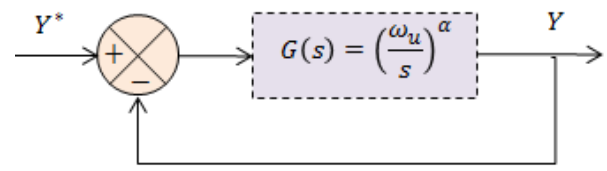

Fig. 7 Functional diagram making of Bode's ideal function loop

The idea is to design a $P I^{\gamma}$ controller such that the closed loop process is similar to a specified fractional order system, as represented in Fig. 7, whose transfer function is Bede's ideal function which is given by:

$$
G_{d}(s)=\frac{G(s)}{1+G(s)}=\frac{1}{1+\left(\frac{s}{\omega_{u}}\right)^{\alpha}}
$$

where, $\omega_{u}$ is a positive real number and $\alpha$ is a real number such that $0<\alpha<2$, and they are chosen such that the specified fractional order model $G_{d}(s)$ system meets the dynamic performance requirements of the projected feedback control system. Indeed, the performance requirements of the projected feedback control system can be given in terms of the unity gain crossover pulsation $\omega_{c}$ and the phase margin $\emptyset_{m}$, parameters $\alpha$ and $\omega_{u}$ which characterise the Bede's ideal function are defined as:

- $\omega_{u}=\omega_{c}\left(\omega_{c}\right.$ is the pulsation corresponding to unity gain of projected feedback control system)

- $\quad \alpha=2\left(1-\left(\emptyset_{m} / \pi\right)\right)\left(\emptyset_{m}\right.$ is the phase margin of projected feedback control system).

In order to design the fractional-order controllers $P I^{\gamma}$ for controlling the DFIG-generator, we have extended the simple method developed by Ramasamy et al. in [28] for the tuning of the parameters of classical PID controller based on the condition $G_{c}(s) \cong G_{d}(s)$ in a given pulsation band around the $\omega_{u}$ corresponding to unity gain.

The Taylor-Maclaurin series development of both transfer functions $G_{c}(s)$ and $G_{d}(s)$ at the $\omega_{u}$ pulsation corresponding to unity gain is presented as:

$$
G_{c}(s)=G_{c}\left(\omega_{u}\right)+\left(s-\omega_{u}\right) G_{c}^{(1)}\left(\omega_{u}\right)+\frac{\left(s-\omega_{u}\right)^{2}}{2 !} G_{c}^{(2)}\left(\omega_{u}\right)+\cdots+
$$




$$
\begin{aligned}
& \frac{\left(s-\omega_{u}\right)^{k}}{k !} G_{c}^{(k)}\left(\omega_{u}\right)+\cdots \\
& G_{d}(s)=G_{d}\left(\omega_{u}\right)+\left(s-\omega_{u}\right) G_{d}^{(1)}\left(\omega_{u}\right)+\frac{\left(s-\omega_{u}\right)^{2}}{2 !} G_{d}^{(2)}\left(\omega_{u}\right)+\cdots+ \\
& \frac{\left(s-\omega_{u}\right)^{k}}{k !} G_{d}^{(k)}\left(\omega_{u}\right)+\cdots
\end{aligned}
$$

where the subscript $(k)$ indicates the derivative of order " $k$ " with respect to variable $s$. The development of TaylorMaclaurin series to the third order term is sufficient to configure three independent equations to determine the parameters $K_{p}, K_{i}$ and $\gamma$. Therefore, in accordance with (35) and (36) we have:

$$
\left\{\begin{array}{c}
G_{c}\left(\omega_{u}\right)=G_{d}\left(\omega_{u}\right) \\
G_{c}^{(1)}\left(\omega_{u}\right)=G_{d}^{(1)}\left(\omega_{u}\right) \\
G_{c}^{(2)}\left(\omega_{u}\right)=G_{d}^{(2)}\left(\omega_{u}\right)
\end{array}\right.
$$

Consequently, the parameters $K_{p}, K_{i}$ and $\gamma$ are to be tuned to according to the system of equations (37).

Let $G_{d}^{(k)}\left(\omega_{u}\right)=\theta_{k}$, for $0 \leq k \leq 2$, so according to (37) and the desired reference model function of (34), we get:

$$
\left\{\begin{array}{c}
G_{d}\left(\omega_{u}\right)=\theta_{0}=\frac{1}{2} \\
G_{d}^{(1)}\left(\omega_{u}\right)=\theta_{1}=-\frac{\alpha}{4 \omega_{u}} \\
G_{d}^{(2)}\left(\omega_{u}\right)=\theta_{2}=\frac{\alpha}{4 \omega_{u}^{2}}
\end{array}\right.
$$

Let $C^{(k)}\left(\omega_{u}\right)=\delta_{k}$ for $0 \leq k \leq 2$, the $\mathrm{i}^{\text {th }}$ derivatives of the transfer function $C(s)$ of fractional order $P I^{\gamma}$ controller at the $s=\omega_{u}$ pulsation corresponding to unity gain.

$$
\left\{\begin{array}{c}
C\left(\omega_{u}\right)=\delta_{0}=K_{p}+\frac{K_{i}}{\left(\omega_{u}\right)^{\gamma}} \\
C^{(1)}\left(\omega_{u}\right)=\delta_{1}=\frac{-\gamma K_{i}}{\left(\omega_{u}\right)^{\gamma+1}} \\
C^{(2)}\left(\omega_{u}\right)=\delta_{2}=\frac{-\gamma(\gamma+1) K_{i}}{\left(\omega_{u}\right)^{\gamma+2}}
\end{array}\right.
$$

The coefficients $\delta_{k}(0 \leq k \leq 2)$ are expressed in function of the coefficients $K_{p}, K_{i}$ and $\gamma$. Therefore, it is sufficient to calculate these three coefficients $\delta_{k}(k=0,1,2)$ to obtain the parameters of fractional order controller.

The feedback control system open loop transfer function $G_{o}(s)$ can be obtained from the closed loop transfer function $G_{c}(s)$ of (32) as:

$$
G_{o}(p)=C(p) G_{p}(p)=\frac{G_{c}(p)}{1-G_{C}(p)}
$$

We denote the derivatives $G_{p}^{(k)}\left(\omega_{u}\right)$, for $0 \leq k \leq 2$, of the function $G_{p}(s)$ with respect to the variable $s$ at the point $s=$ $\omega_{u}$ by:

$$
\left\{\begin{array}{c}
G_{p}\left(\omega_{u}\right)=\mu_{0} \\
G_{p}^{(1)}\left(\omega_{u}\right)=\mu_{1} \\
G_{p}^{(2)}\left(\omega_{u}\right)=\mu_{2}
\end{array}\right.
$$

Using the equations system (37)-(39), the derivatives $G_{o}^{(k)}\left(\omega_{u}\right)$, for $0 \leq k \leq 2$, of the function $G_{o}(s)$ with respect to the variable $s$ at the point $s=\omega_{u}$ are calculated as:

$$
\left\{\begin{array}{c}
G_{o}\left(\omega_{u}\right)=\delta_{0} \mu_{0}=\frac{\theta_{0}}{1-\theta_{0}} \\
G_{o}^{(1)}\left(\omega_{u}\right)=\delta_{1} \mu_{0}+\delta_{0} \mu_{1}=\frac{\theta_{1}}{\left(1-\theta_{0}\right)^{2}} \\
G_{o}^{(2)}\left(\omega_{u}\right)=\delta_{2} \mu_{0}+2 \delta_{1} \mu_{1}+\delta_{0} \mu_{2}=\frac{\theta_{2}}{\left(1-\theta_{0}\right)^{2}}+\frac{\theta_{1}^{2}}{\left(1-\theta_{0}\right)^{3}}
\end{array}\right.
$$

As indicated before, the design of FOPI controller is based on the impulse response of the process controlled; and it does not require any approximation of the process by a model. In this design method, the expression of the functions $G_{p}^{(k)}\left(\omega_{u}\right)$, for $0 \leq k \leq 2$, are determined in function of its impulse response. The transfer function $G_{p}(s)$ of the process can be obtained from its impulse response noted $g_{p}(t)$ as:

$$
G_{p}(s)=\int_{0}^{+\infty} g_{p}(t) e^{-s t} d t
$$

As we can apply Taylor-Maclaurin series expansion at $s=$ $\omega_{u}$ for the function $e^{-s t}$, the expression of $G_{p}(s)$ becomes:

$$
\begin{aligned}
& G_{p}(s)=\int_{0}^{+\infty} g_{p}(t)\left(e^{-\omega_{u} t}-\left(s-\omega_{u}\right)\left(t e^{-\omega_{u} t}\right)+\right. \\
& \left.\frac{\left(s-\omega_{u}\right)^{2}}{2 !}\left(t^{2} e^{-\omega_{u} t}\right)+\cdots\right) d t \\
& G_{p}(s)=\int_{0}^{+\infty}\left(g_{p}(t) e^{-\omega_{u} t}\right) d t+\left(s-\omega_{u}\right) \int_{0}^{+\infty}\left(-t e^{-\omega_{u} t}\right) d t+ \\
& \frac{\left(s-\omega_{u}\right)^{2}}{2 !} \int_{0}^{+\infty}\left(t^{2} e^{-\omega_{u} t}\right) d t+\ldots
\end{aligned}
$$

On the other hand, the Taylor-Maclaurin series expansion of the function $G_{p}(s)$ at the $\omega_{u}$ pulsation corresponding to unity gain is given as:

$$
\begin{aligned}
& G_{p}(s)=G_{p}\left(\omega_{u}\right)+\left(s-\omega_{u}\right) G_{p}^{(1)}\left(\omega_{u}\right)+\frac{\left(s-\omega_{u}\right)^{2}}{2 !} G_{p}^{(2)}\left(\omega_{u}\right)+\cdots+ \\
& \frac{\left(s-\omega_{u}\right)^{k}}{k !} G_{p}^{(k)}\left(\omega_{u}\right)+\cdots
\end{aligned}
$$

So, by identification technique for (45) and (46) we get:

$$
\left\{\begin{array}{c}
\mu_{0}=G_{p}\left(\omega_{u}\right)=\int_{0}^{+\infty} g_{p}(t) e^{-\omega_{u} t} d t \\
\mu_{1}=G_{p}^{(1)}\left(\omega_{u}\right)=-\int_{0}^{+\infty} t e^{-\omega_{u} t} d t \\
\mu_{2}=G_{p}^{2}\left(\omega_{u}\right)=\int_{0}^{+\infty} t^{2} e^{-\omega_{u} t} d t
\end{array}\right.
$$

Since the frequency corresponding to unity gain $\omega_{u}$ is positive and the integer $n \geq 0$, we have $\lim _{t \rightarrow \infty} t^{n} e^{-\omega_{u} t}=0$, then the integrals $\mu_{k}$, for $0 \leq k \leq 2$, of (46) converge and can be determined numerically employing following formulas:

$$
\left\{\begin{array}{c}
\mu_{0=} G_{p}\left(\omega_{u}\right)=\sum_{l=0}^{n} g_{p}(l T) e^{-l T \omega_{u}} \\
\mu_{1}=G_{p}^{(1)}\left(\omega_{u}\right)=-\sum_{l=0}^{n}(l T) g_{p}(l T) e^{-l T \omega_{u}} \\
\mu_{2}=G_{p}^{2}\left(\omega_{u}\right)=\sum_{l=0}^{n}(l T)^{2} g_{p}(l T) e^{-l T \omega_{u}}
\end{array}\right.
$$

where $T=1 / f_{\text {sam }}$ and $f_{\text {sam }}$ are the frequency of the impulse response $g_{p}(t)$ of the process and the number of samples 
$n$ =integer part of $\left\{T_{a c} / T\right\}$, with $T_{a c}$ being the weather of acquisition of the impulse response. Like that the numerical values of the coefficients $\mu_{k}$, for $0 \leq k \leq 2$, are calculated from the obtained numerical values of the step response $g_{p}(t)$ of the process and the unity gain crossover pulsation $\omega_{u}$. The coefficients $\mu_{k}$ can also be obtained directly from the transfer function of the process if it is available. Consequently, according to (42) and (48) we can determine the values of $\delta_{0}$, $\delta_{1}$ and $\delta_{2}$ as:

$$
\left\{\begin{array}{c}
\delta_{0}=\frac{\theta_{0}}{\mu_{0}\left(1-\theta_{0}\right)} \\
\delta_{1}=\frac{\theta_{1}}{\mu_{0}\left(1-\theta_{0}\right)^{2}}-\frac{\delta_{0} \mu_{1}}{\mu_{0}} \\
\delta_{2}=\frac{\theta_{2}}{\mu_{0}\left(1-\theta_{0}\right)^{2}}+\frac{2 \theta_{1}^{2}}{\mu_{0}\left(1-\theta_{0}\right)^{3}}-\frac{2 \delta_{1} \mu_{1}+\delta_{0} \mu_{2}}{\mu_{0}}
\end{array}\right.
$$

Once the coefficients $\delta_{k}$, for $0 \leq k \leq 2$, are obtained, the design arrives the final step and the parameters $K_{p}, K_{i}$ and $\gamma$ can be calculated.

$$
\left\{\begin{array}{c}
\gamma=-\frac{\omega_{u} \delta_{2}}{\delta_{1}}-1 \\
K_{i}=-\frac{\delta_{1} \omega_{u}^{(\gamma+1)}}{\gamma} \\
K_{p}=\delta_{0}-K_{i} \omega_{u}^{-\gamma}
\end{array}\right.
$$

\section{FOPI DESIGN FOR CONTROL DFIG-GENERATOR}

After presenting the simple analytical method for tuning the parameters $\gamma, K_{i}$ and $K_{p}$ of the fractional order controller; this design method is applied for the inner and outer control loops of the RSC in the next subsections.

Fig. 8 showed the proposed control diagram of the RSC control using FOPI controllers in the $q$ axis according to vector control approach. In this figure, the term $C_{d \rightarrow q}=$ $g \omega_{s} \sigma L_{r} I_{r d}$ represented the cross coupling between $d$ and $q$ axis and $F_{q}=g L_{m} V_{s} / L_{s}$ is the disturbance term. These two terms depend strongly on DFIG slip; but, in the majority of operating cases, DFIG-generator operates around synchronous speed; accordingly, these terms do not have significant effect in the steady state working mode and could be compensated by adding feed-forward terms, as shown in Fig. 8 .

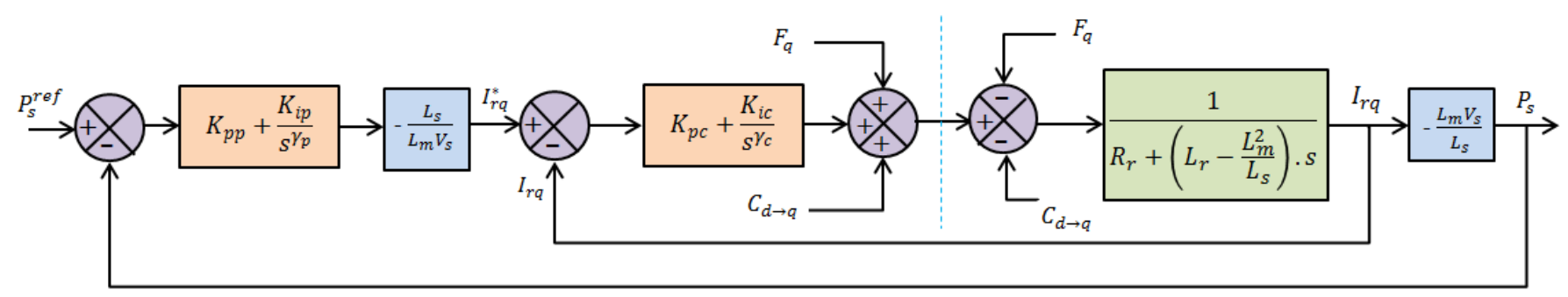

Fig. 8 The proposed block diagram for applying FOPI controllers in the RSC

\section{A. Design of the Rotor Current Loop Controller}

The inner loop control is introduced to control the rotor current as described in the control scheme in Fig. 8, the transfer function of open loop $\left(\mathrm{TFOL}_{\mathrm{c}}\right)$ including the $\mathrm{PI}^{\gamma}$ controller for internal loop of the rotor current control is expressed by (51):

$$
T F O L_{c}=\left(K_{p c}+\frac{K_{i c}}{s^{\gamma} \gamma_{c}}\right) \frac{1}{R_{r}+\left(L_{r}-\frac{L_{m}^{2}}{L_{s}}\right) s}
$$

In accordance with the developed simple analytical method for designing the FOPI controller, we consider the dynamic performance requirements of the projected feedback control system as the unity gain frequency $\omega_{u}=500 \mathrm{rad} / \mathrm{s}$ and the phase margin $\emptyset_{m}=65^{\circ}$. Consequently, the parameter $\alpha$ which specifies Bede's ideal function is calculated as follows:

$$
G_{d}(s)=\frac{G(s)}{1+G(s)}=\frac{1}{1+\left(\frac{s}{500}\right)^{1.278}}
$$

The values of $\mu_{0}, \mu_{1}$ and $\mu_{2}$ are calculated from the block diagram of Fig. 8 as:

$$
\begin{gathered}
\mu_{0}=\left[\frac{1}{R_{r}+\left(L_{r}-\frac{L_{m}^{2}}{L_{s}}\right) \omega}\right]_{\omega=\omega_{u}}=7,42.10^{-2} \\
\mu_{1}=\frac{d}{d \omega}\left[\frac{1}{R_{r}+\left(L_{r}-\frac{L_{m}^{2}}{L_{s}}\right) \omega}\right]_{\omega=\omega_{u}}=\left[\frac{-\left(L_{r}-\frac{L_{m}^{2}}{L_{s}}\right)}{\left(R_{r}+\left(L_{r}-\frac{L_{m}^{2}}{L_{s}}\right) \omega\right)^{2}}\right]_{\omega=\omega_{u}} \\
==>\quad \mu_{1}=-1,48.10^{-4} \\
\mu_{2}=\frac{d^{2}}{d^{2} \omega}\left[\frac{1}{R_{r}+\left(L_{r}-\frac{L_{m}^{2}}{L_{S}}\right) \omega}\right]_{\omega=\omega_{u}}=\frac{d}{d \omega}\left[\frac{-\left(L_{r}-\frac{L_{m}^{2}}{L_{s}}\right)}{\left(R_{r}+\left(L_{r}-\frac{L_{m}^{2}}{L_{s}}\right) \omega\right)^{2}}\right]_{\omega=\omega_{u}}= \\
{\left[\frac{2\left(L_{r}-\frac{L_{m}^{2}}{L_{s}}\right)^{2}}{\left(R_{r}+\left(L_{r}-\frac{L_{m}^{2}}{L_{s}}\right) \omega\right)^{3}}\right]_{\omega=\omega_{u}}=5,92.10^{-7}}
\end{gathered}
$$

From (52), the values of coefficients $\theta_{0}, \theta_{1}$ and $\theta_{2}$ are:

$$
\theta_{0}=0.5, \theta_{1}=-6,38.10^{-4}, \theta_{2}=1,278.10^{-6}
$$

As a result, the transfer function of $P I^{\gamma_{c}}$ controller obtained by applying the developed design method, for the rotor current control loop, is given by: 


$$
C(s)=k_{p c}+\frac{K_{i c}}{s^{\gamma} \gamma_{c}}=0,263+\frac{77,59}{s^{0.285}}
$$

The Bode magnitude and phase diagrams of open loop transfer functions for the projected feedback control system (the transfer function of rotor current control loop) and for the desired fractional model according to (52) are shown in Fig. 9. From this figure, the open loop transfer function of the feedback control system is quite overlapping with the open loop transfer function $(s / 500)^{-1,278}$ of the desired fractional order model in the frequency band of interest $\left[\sim 30 ; 2.10^{4}\right]$ $\mathrm{rad} / \mathrm{s}$. We also note in this frequency range that the transfer function of the projected feedback control system has the same behavior as that of the reference model. It means that the unity gain crossover pulsation $\omega_{\mathrm{u}}$ and the phase margin $\emptyset_{\mathrm{m}}$ of the feedback control system is $\omega_{\mathrm{u}}=500 \mathrm{rad} / \mathrm{s}$ and $\emptyset_{\mathrm{m}}=65^{\circ}$. We note also the flatness of the phase around the crossover pulsation $\omega_{\mathrm{u}}$.

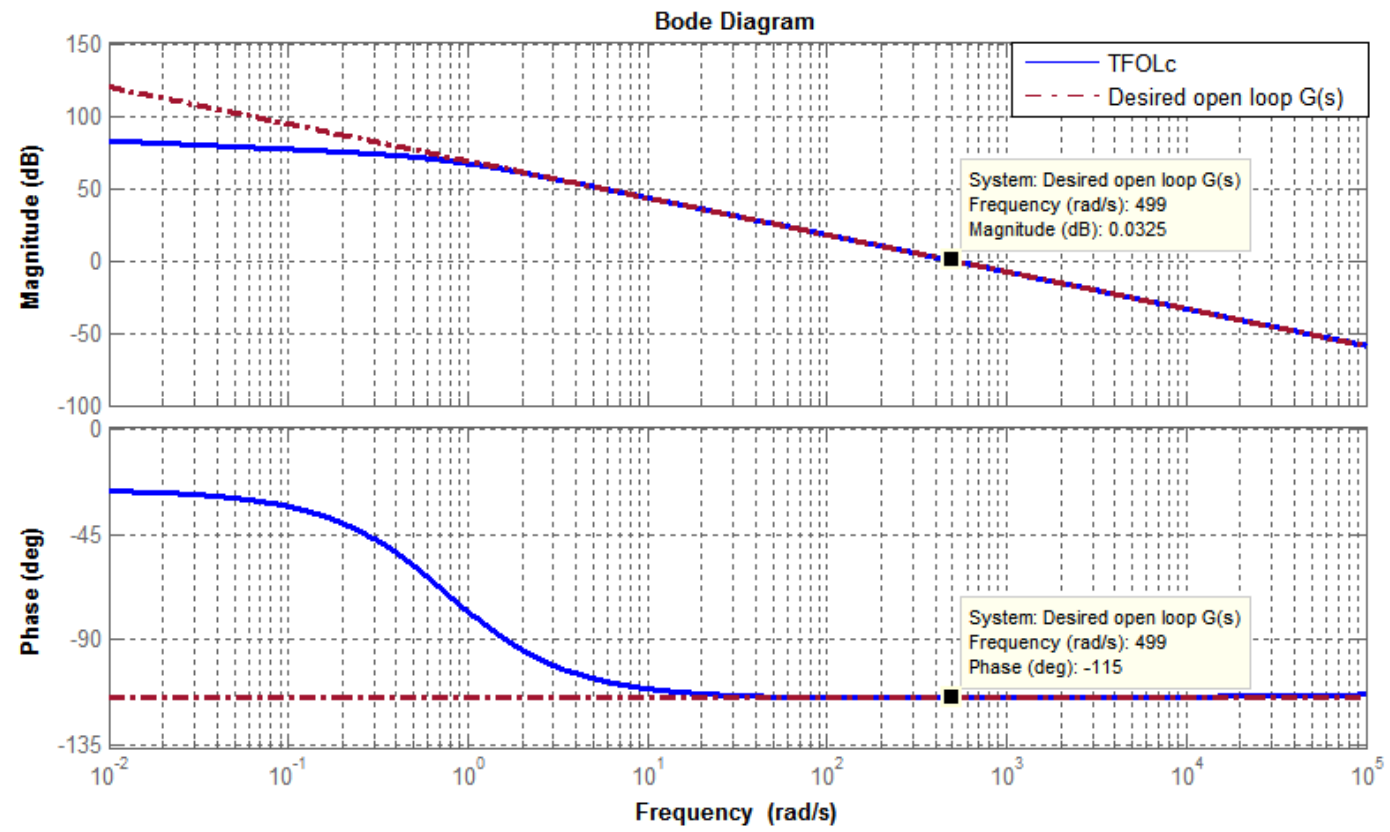

Fig. 9 Bode magnitude and phase diagrams of open loop transfer function of the rotor current control and open loop transfer function of desired model

\section{B. Design of the Power Loop Controller}

In this subsection we formulate a fractional order $P I^{\gamma}$ to regulate the active power $\left(P_{S}\right)$. According to control scheme shown in Fig. 8, the open loop transfer function of the active power control loop with FOPI controller is expressed as:

$$
T F O L_{p}=\left(K_{p p}+\frac{K_{i p}}{s^{\gamma p}}\right) \frac{\left(\mathrm{K}_{\mathrm{pc}}+\frac{\mathrm{K}_{\mathrm{ic}}}{\mathrm{\gamma}^{\gamma /}}\right)}{\mathrm{R}_{\mathrm{r}}+\left(\mathrm{L}_{\mathrm{r}}+\frac{\mathrm{L}_{\mathrm{m}}^{2}}{\mathrm{~L}_{\mathrm{s}}}\right) \mathrm{s}+\left(\mathrm{K}_{\mathrm{pc}}+\frac{\mathrm{K}_{\mathrm{ic}}}{\mathrm{s} \gamma \mathrm{c}}\right)}
$$

Similarly, for the power control loop we consider the dynamic performances requirements of the projected feedback control system as the unity gain pulsation $\omega_{u}=500$ rads and the phase margin $\emptyset_{m}=65^{\circ}$, and consequently the parameter $\alpha$ which specifies Bede's ideal function is calculated as: $\alpha=$ $2\left(1-\left(\frac{\emptyset_{m}}{\pi}\right)\right)=1,278$.

As result, the performance requirements are satisfied by the reference model whose transfer function is described as:

$$
G_{d}(s)=\frac{G(s)}{1+G(s)}=\frac{1}{1+\left(\frac{s}{500}\right)^{1,278}}
$$

Pursuant to (55), the values of coefficients $\theta_{0}, \theta_{1}$ and $\theta_{2}$ are: $\theta_{0}=0.5, \theta_{1}=-6,38 \cdot 10^{-4}, \theta_{2}=1,278 \cdot 10^{-6}$.

The values of $\mu_{0}, \mu_{1}$ and $\mu_{2}$ are calculated as:

$\mu_{0}=\left[\frac{\left(K_{p c}+\frac{K_{i c}}{\omega^{\gamma c}}\right)}{R_{r}+\left(L_{r}+\frac{L_{m}^{2}}{L_{S}}\right) \omega+\left(K_{p c}+\frac{K_{i c}}{\omega^{\gamma} c}\right)}\right]_{\omega=\omega_{u}}=0,5$

$\mu_{1}=\frac{d}{d \omega}\left[\frac{\left(K_{p c}+\frac{K_{i c}}{\omega^{\gamma} c}\right)}{R_{r}+\left(L_{r}+\frac{L_{m}^{2}}{L_{S}}\right) \omega+\left(K_{p c}+\frac{K_{i c}}{\omega^{\gamma} c}\right)}\right]_{\omega=\omega_{u}}=$

$\left[\frac{-\frac{\gamma_{c} K_{i c}}{\omega^{\gamma} c+1}}{R_{r}+\left(L_{r}+\frac{L_{m}^{2}}{L_{S}}\right) \omega+\left(K_{p c}+\frac{K_{i c}}{\omega^{\gamma} c}\right)}-\frac{\left(K_{p c}+\frac{K_{i c}}{\omega^{\gamma} c}\right)\left(\left(L_{r}+\frac{L_{m}^{2}}{L_{S}}\right)-\frac{\gamma_{c} K_{i c}}{\omega^{\gamma} c+1}\right)}{\left(R_{r}+\left(L_{r}+\frac{L_{m}^{2}}{L_{S}}\right) \omega+\left(K_{p c}+\frac{K_{i c}}{\left.\omega^{\gamma}\right)}\right)\right]_{\omega=\omega_{u}}^{2}}=\right.$

$-6,38 \cdot 10^{-4}$

$\mu_{2}=\frac{d^{2}}{d^{2} \omega}\left[\frac{\left(K_{p c}+\frac{K_{i c}}{\omega^{\gamma} c}\right)}{R_{r}+\left(L_{r}+\frac{L_{m}^{2}}{L_{S}}\right) \omega+\left(K_{p c}+\frac{K_{i c}}{\omega^{\gamma} c}\right)}\right]_{\omega=\omega_{u}}=$

$\left[\frac{\frac{\gamma_{c}\left(\gamma_{c}+1\right) K_{i c}}{\omega^{\gamma}+2}}{R_{r}+\left(L_{r}+\frac{L_{m}^{2}}{L_{S}}\right) \omega+\left(K_{p c}+\frac{K_{i c}}{\omega^{\gamma}}\right)}+2 \frac{\frac{\gamma_{c} K_{i c}}{\omega^{\gamma} \gamma_{c+1}}\left(\left(L_{r}+\frac{L_{m}^{2}}{L_{S}}\right)-\frac{\gamma_{c} K_{i c}}{\omega^{\gamma} \gamma_{c+1}}\right)}{\left(R_{r}+\left(L_{r}+\frac{L_{m}^{2}}{L_{S}}\right) \omega+\left(K_{p c}+\frac{K_{i c}}{\omega^{\gamma} C}\right)\right)^{2}}-\right.$ 


$$
\begin{aligned}
& \frac{\frac{\gamma_{c}\left(\gamma_{c}+1\right) K_{i c}}{\omega^{\gamma} c+2}\left(K_{p c}+\frac{K_{i c}}{\omega^{\gamma} c}\right)}{\left(R_{r}+\left(L_{r}+\frac{L_{m}^{2}}{L_{S}}\right) \omega+\left(K_{p c}+\frac{K_{i c}}{\omega^{\gamma} c}\right)\right)^{2}}+ \\
& \left.2 \frac{\left(\left(L_{r}+\frac{L_{m}^{2}}{L_{S}}\right)-\frac{\gamma_{c} K_{i c}}{\omega^{\gamma} c+1}\right)^{2}\left(K_{p c}+\frac{K_{i c}}{\left.\omega^{\gamma}\right)}\right.}{\left(R_{r}+\left(L_{r}+\frac{L_{m}^{2}}{L_{S}}\right) \omega+\left(K_{p c}+\frac{K_{i c}}{\omega^{\gamma}}\right)\right)^{3}}\right]_{\omega=\omega_{u}}=1,278.10^{-6}
\end{aligned}
$$

Accordingly, the transfer function $P I^{\gamma p}$ controller for the active power control loop is given by:

$$
C(s)=K_{p p}+\frac{K_{i p}}{s^{\gamma p}}=1+\frac{2,8 \cdot 10^{3}}{s^{1.278}}
$$

The Bode magnitude and phase diagrams of transfer function of the active power control loop and the desired fractional model $G_{d}(s)$ are illustrated in Fig. 10. From this figure, the open loop transfer function of the feedback control system is quite overlapping with the open loop transfer function $(\mathrm{s} / 500)^{-1.278}$ of the desired fractional order model of $(55)$ in the pulsation band of interest $\left[\sim 10^{-2} ; 3.10^{3}\right] \mathrm{rad} / \mathrm{s}$. It means that the unity gain crossover pulsation and the phase margin of the feedback control system are $\omega_{\mathrm{u}}=500 \mathrm{rad} /$ $\mathrm{s}$ and $\emptyset_{\mathrm{m}}=65^{\circ}$. We note also the flatness of the phase around the crossover pulsation $\omega_{\mathrm{u}}=500 \mathrm{rad} / \mathrm{s}$, so we can say that we obtain a robust control.

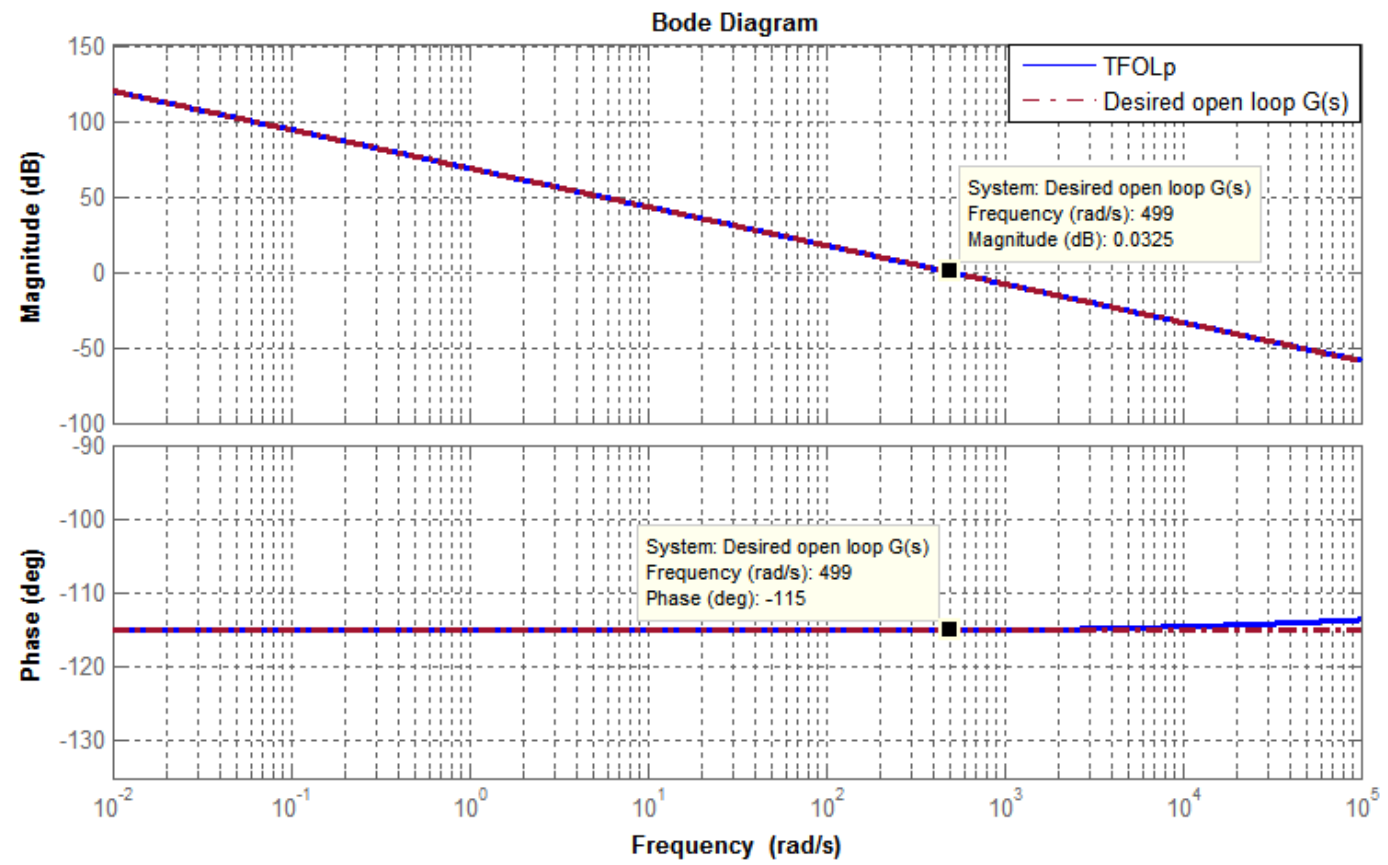

Fig. 10 Bode magnitude and phase diagrams of open loop transfer function of the active power control loop and open loop transfer function of desired model

\section{PERformance Evaluation \& Discussion}

In this section, simulation results are obtained beneath various operating conditions to evaluate performances of designed FOPI controller, and to validate the advantages of proposed $\mathrm{PI}^{\gamma}$ controller in comparison with the IOPI controller for the studied wind energy generation system based on a 1.5 MW DFIG prototype. In this work, the IOPI controllers used in the control loops of rotor side static converter are formulated by pole-cancelation method as applied in [46]. The complete WGS based on DFIG- generator was simulated by MATLAB/Simulink. The standard values of the parameters employed in the simulations are listed in Table I (see Appendix). The controller developed is applied in the RSC to control energy exchange between the DFIG and electric power grid. In regards to the DFIG, side converter is controlled to regulate the stator active power $P_{S}$, such that the WGS operates at the optimal operating point with use of MPPT control strategy; while the, the stator reactive power $\left(Q_{s}\right)$ is controlled to minimize the generator Joule losses
$\left(Q_{s-r e f}=2 \cdot 10^{5} V A R\right)$. On the other hand, the DC-link voltage reference is fixed at $U_{d c}=1200 \mathrm{~V}$ and the electric grid frequency value is steady at $50 \mathrm{~Hz}$. The wind speed profile applied to wind turbine is illustrated in Fig. 11. In response to this wind speed profile, the generator speed almost has the same image as the wind speed, as presented in Fig. 12 (a). This figure shows also that the generator speed follows its optimal reference very well. Fig. 12 (b) illustrates the power coefficient which is maintained at its maximum value $C_{p_{-} \max }=0.48$ over the entire range of wind speed. The TSR is conserved at its optimum $\lambda_{\text {opt }}=8.1$, as presented in Fig. 12 (c). This means that the MPPT algorithm is working perfectly to extract the maximum power transported by the air masses. 


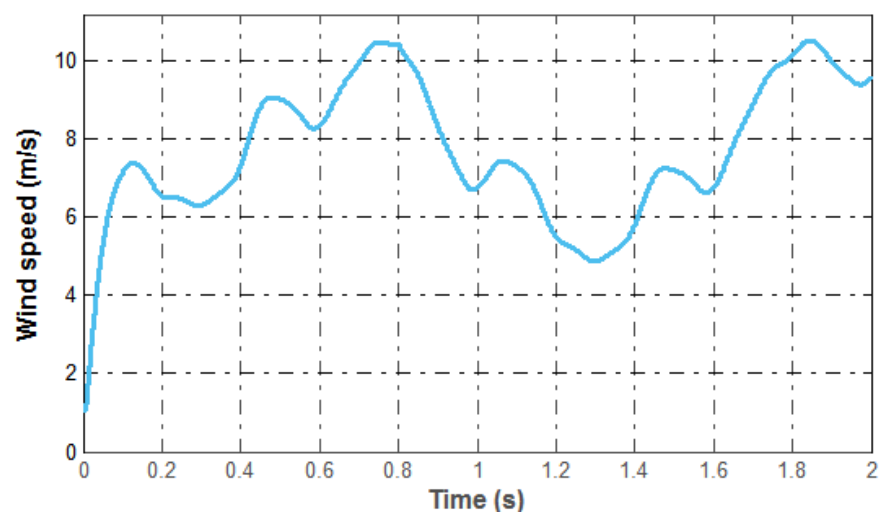

Fig. 11 Wind speed profile

In first test, we considered that the system operating under ideal condition without any faults, parametric uncertainty and no external disturbance. In this case the wind turbine is driven by the wind speed profile illustrated previously in Fig. 11 and the WGS operates under MPPT strategy. Fig. 13 shows the performances of the $\mathrm{PI}^{\gamma}$ controller proposed and the IOPI controller for trajectory tracking, respectively.

In response to the wind speed sequence considered, the stator active power supplied to the electric power grid is proportional to cube of the wind speed, and it follows its reference brought from the MPPT control strategy in order to exploit well the wind energy source.

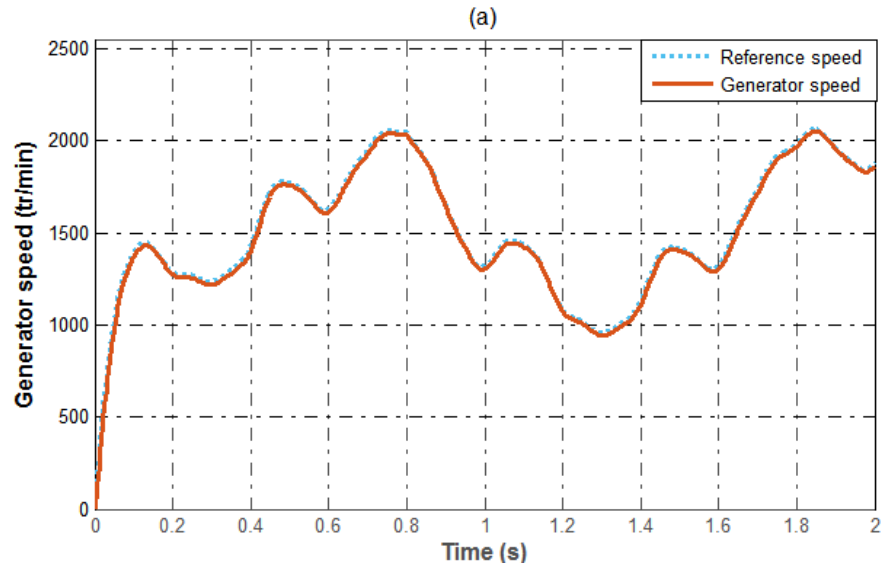

(b)

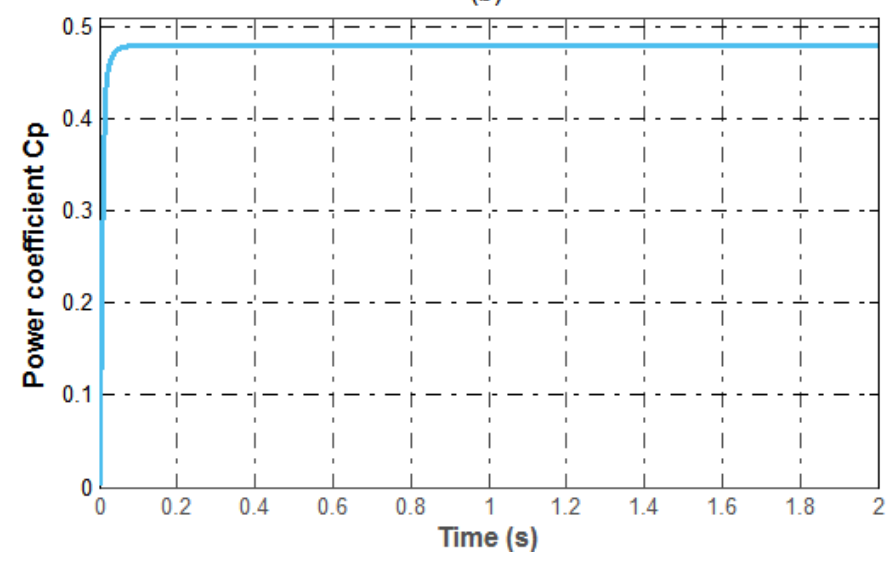

(c)

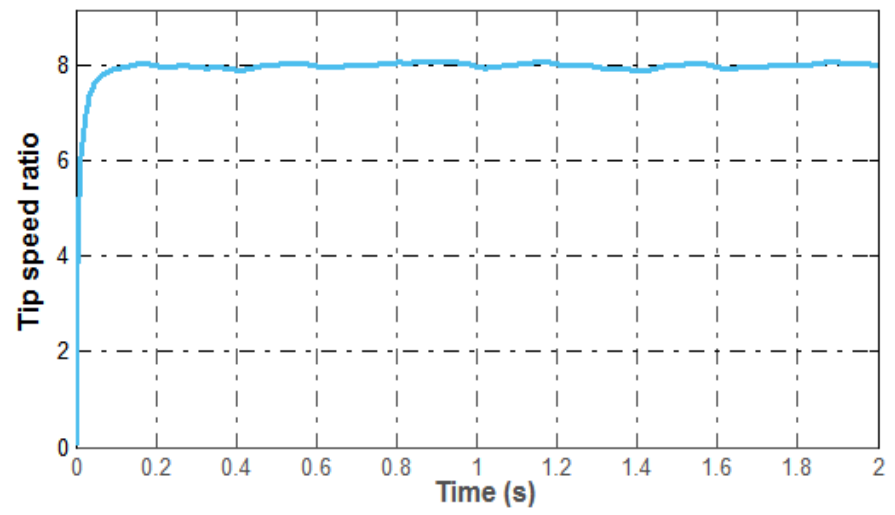

Fig. 12 Rotational speed response in MPPT operating mode; (a):

Rotational speed response; (b): Power coefficient; (c): Tip speed ratio

The resulting stator reactive power, exchanged between DFIG stator and grid, follows its reference imposed in order to minimize the generator Joule losses. The reference signals of the direct- and quadrature-axis components of the rotor currents are obtained from the controllers outputs of the control loops of the reactive power and active power, respectively.

The active and reactive powers waveforms are enlarged from 0.5 to $0.85 \mathrm{~s}$ and from 0.5 to $1 \mathrm{~s}$ respectively in Fig. 14 for better illustrations. The simulation results illustrated that the tracking performance of the proposed controller is better as compared to the IOPI controller. The responses of the closedloop system in case of FOPI controller highlight an obvious enhancement of the performances in transient regime (overshoot, transient time) and a reduction of the overshoot. Indeed, the designed FOPI controller exhibits the fastest convergence time. Moreover, the tracking performance with the proposed fractional control is more accurate.

In order to be able to assess the quality of the signal provided by the DFIG, a Fast Fourier Transform (FFT) analysis of one phase stator current waveforms was carried out for 3 cycles of operation starting at $0.4 \mathrm{~s}$ and for a harmonic order of 30. The measured THD (total harmonic distortion) is presented in Fig. 15. The analysis showed that Fractional order $P I^{\gamma}$ controller provides a lower THD in comparison with the IOPI controller. Indeed, for phase (a) stator current with the IOPI controller, the THD rate is $2.08 \%$ while in the case of the FOPI controller, the THD rate is $1.47 \%$. The efficiency of WGS is enhanced by introducing FOPI controller whose integral order is fractional. The increase in tuning parameters of Fractional order $\mathrm{PI}^{\gamma}$ controller, and the increases of the robustness of the system, provide optimal control and deliver better system response than IOPI controller.

In second test, the performance of WGS is tested under external disturbance conditions and wind speed variation. Indeed, a disturbance of random output noise of $20 \%$ of the reference signal amplitude is applied from $\mathrm{t}=0.5 \mathrm{~s}$ to $\mathrm{t}=1.5 \mathrm{~s}$ on the output of rotor currents and the turbine is exposed to the wind speed sequence illustrated previously in Fig. 11. The obtained performance assessment results, when the system is 

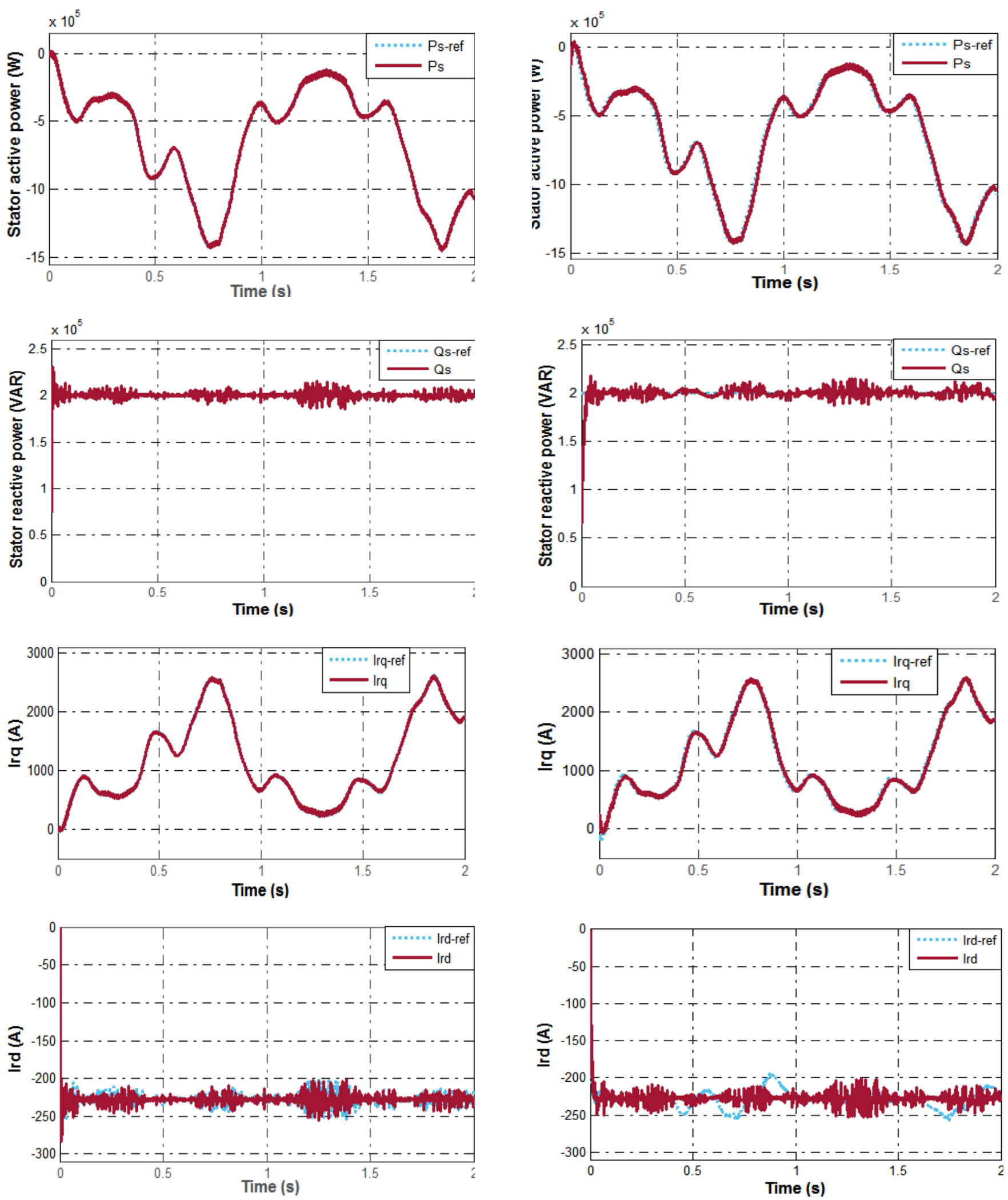

Fractional order $P I^{\gamma}$ controller

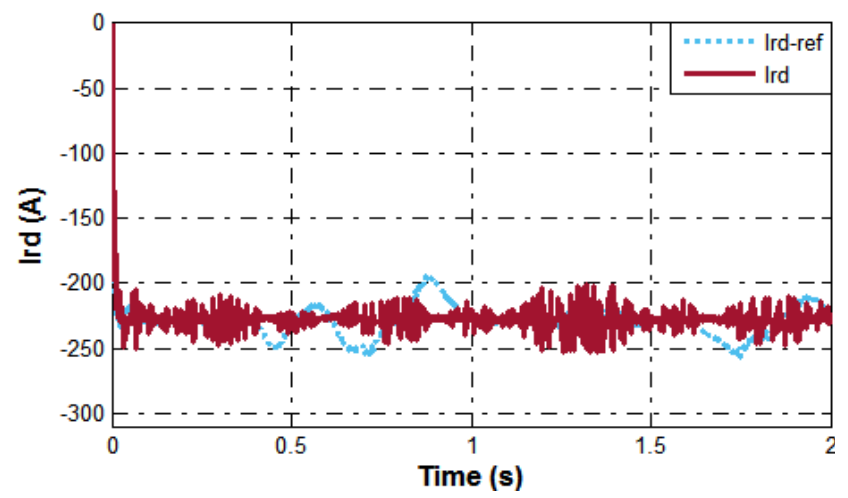

IOPI controller

Fig. 13 Performance for trajectory tracking of the fractional order $P I^{\gamma}$ controller proposed and the IOPI controller 

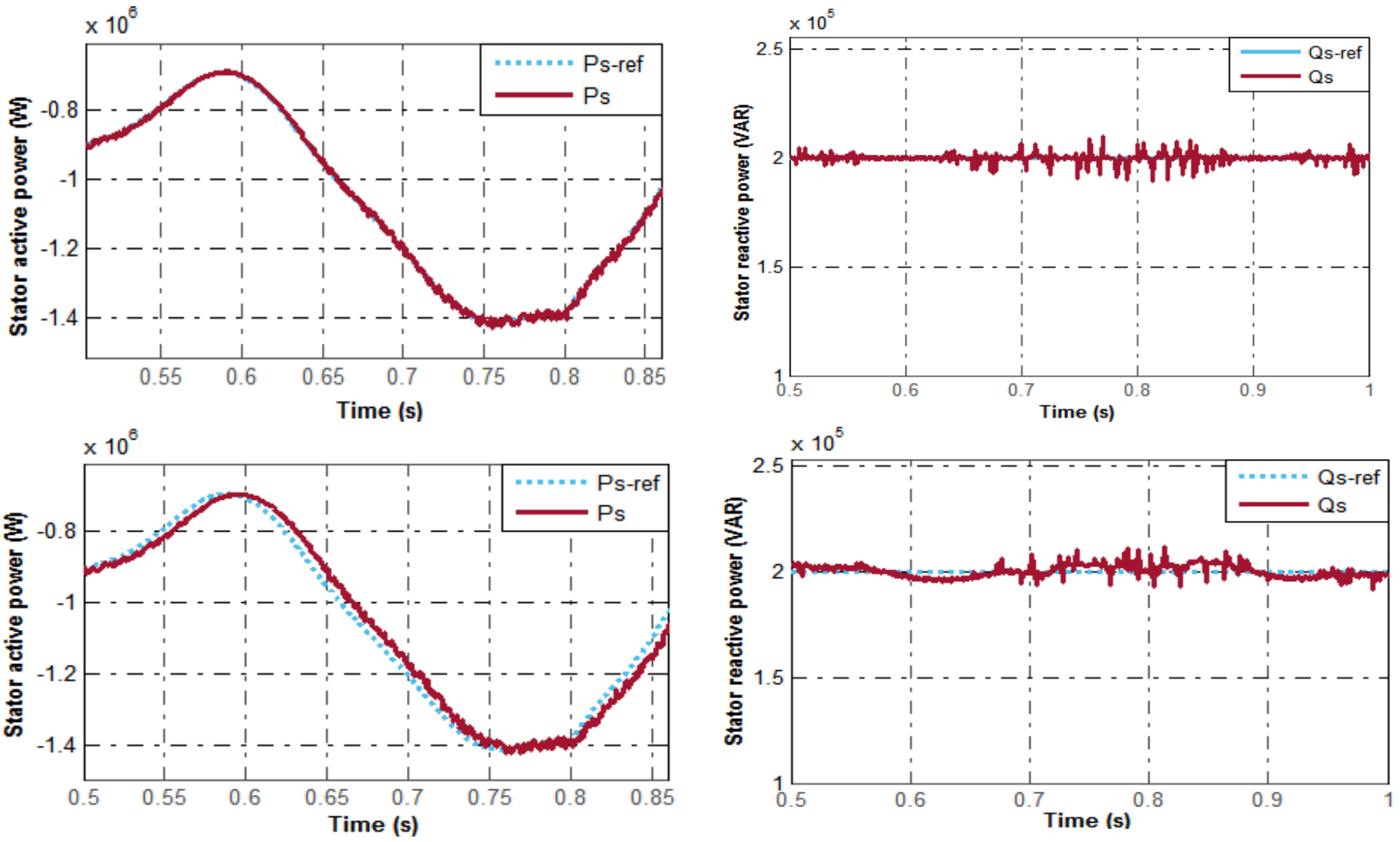

Fractional order $P I^{\gamma}$ controller

IOPI controller

Fig. 14 Enlarged active and reactive powers waveforms of fractional order PI and IOPI controllers
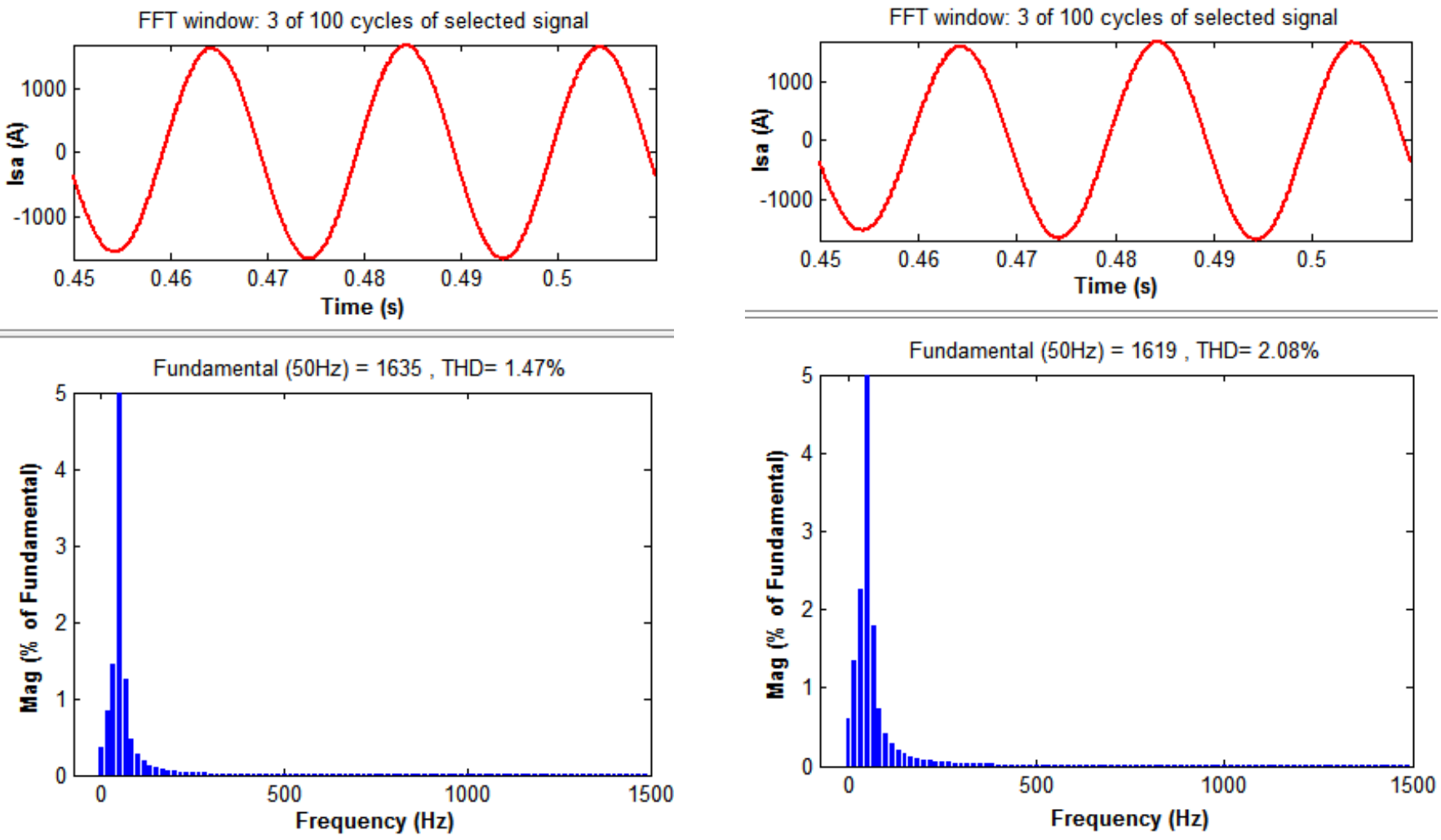

Fractional order $P I^{\gamma}$ controller

IOPI controller

Fig. 15 Spectrum harmonic of phase (a) stator current 

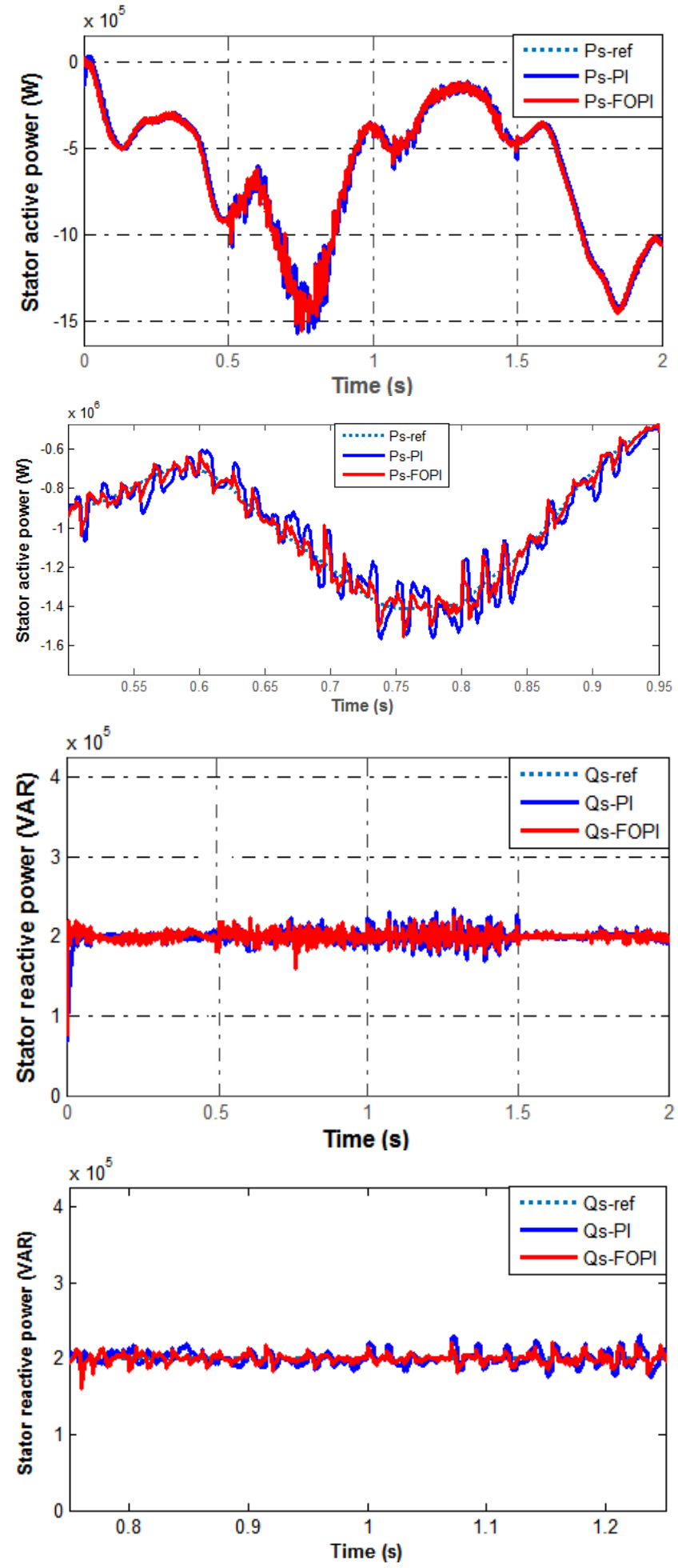

Fig. 16 Stator active and reactive power waveforms

operating under external disturbance, are shown in Figs. 16 and 17 which allow us quantitatively evaluating the benefits achievable with fractional controllers. Fig. 16 presents the waveforms of stator active and reactive power, as well as their enlargement from $0.5 \mathrm{~s}$ to $0.95 \mathrm{~s}$ and from $0.75 \mathrm{~s}$ to $1.25 \mathrm{~s}$ respectively for better illustrations, under the described operating conditions. According to this figure, the stator active and reactive power tracks perfectly its reference for both controllers. But the external disturbance causes oscillations in the generated powers from DFIG mostly during periods of high wind power availability. We can see that in this figure the IOPI controller presents high ripples and the $P I^{\gamma}$ controller provides a better response and less ripples. Despite oscillations visually present in the stator active and reactive power waveforms for FOPI controller, the aforementioned results reveal that the designed controller presented better performance compared with the IOPI controller. As result, with the Fractional order $P I^{\gamma}$ controller the signals tracks their references faster, robustly and less responsive to the disturbances.

In order to illustrate the advantages of the FOPI controller concerning the energy quality delivered to electric power grid, a FFT analysis of stator currents in presence the external disturbance is shown in Fig. 17 for both controllers. The FFT analysis of phase stator current waveforms was carried out for 3 cycles of operation starting at $0.75 \mathrm{~s}$ and for a harmonic order of 30. The analysis showed that the FOPI controller provides a lower THD in comparison with the IOPI controller. Indeed, for phase (a) stator current with the IOPI controller, the THD rate is $5.25 \%$ while in the case of the fractional $P I^{\gamma}$ controller, the THD rate is $3.44 \%$. Consequently, the significant improvement in THD reduction is attained by FOPI compared with the IOPI controller.
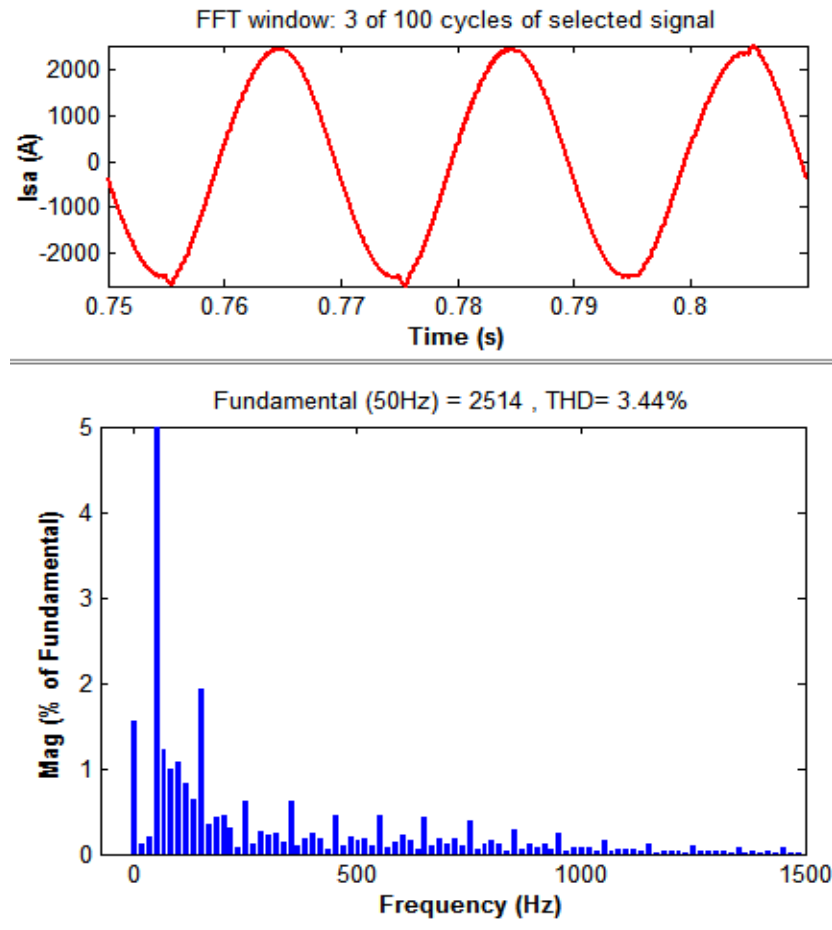

Fractional order $P I^{\gamma}$ controller 

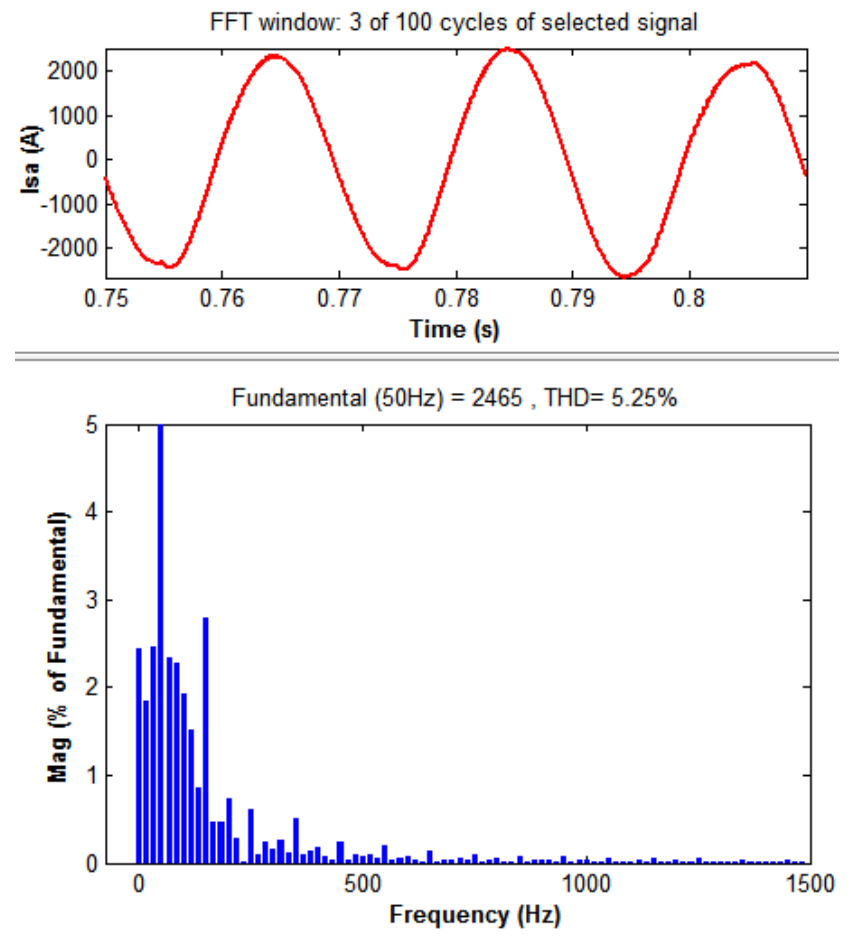

IOPI controller

Fig. 17 FFT analysis of phase (a) stator current

\section{VIII.CONCLUSIONS}

In this paper, a fractional order $\mathrm{PI}^{\gamma}$ controller is proposed instead of the IOPI controller to improve the performance of the variable speed WGS based on the DFIG-generator. The designed FOPI controller is based on improving the efficiency of IOPI controller by using the fractional integrator of order " $\gamma$ ", instead of the integer order integrator. The simulation has been performed in MATLAB/Simulink to compare the performance of WGS, controlled according to vector control approach using the designed fractional $P I^{\gamma}$ controller instead of using the standard one. According to the results obtained, the main objectives were achieved. It becomes clear that the system dynamic performance using proposed FOPI controllers is much better than IOPI controllers, such as: the perfect tracking of the references, the fastest convergence of time and the more accurate tracking performance. Also the proposed controller increases the robustness of the system. Moreover, the spectrum THD of the stator currents showed a lower THD, which means an improvement of the quality of the power injected in to grid. Consequently, this feature of FOPI controller improves the system efficiency by reducing the losses caused by harmonics content of the courant. These results are attractive for wind power applications to ensure stability and quality of the created power.

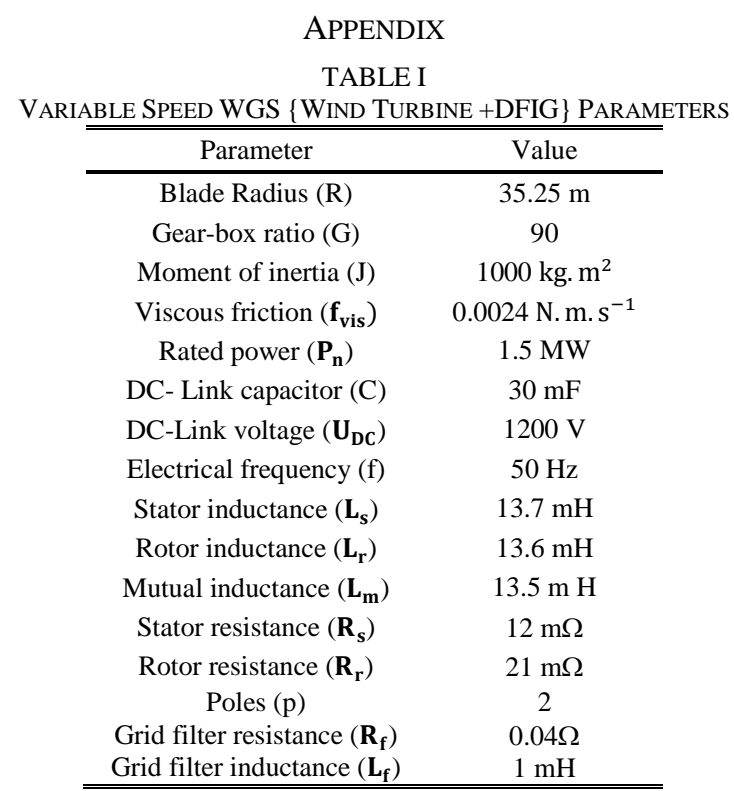

\section{REFERENCES}

[1] Abdelbaset A, Mohamed YS, El-Sayed AHM, Ahmed AEHA. Wind Driven Doubly Fed Induction Generator. Power Systems 2018, Springer International Publishing AG 2018, https://doi.org/10.1007/978-3-31970108-0_2.

[2] Kesraouia M, Chaib A, Meziane A, Boulezaz A. Using a DFIG based wind turbine for grid current harmonics filtering. Energy Conversion and Management 78 (2014) 968-975.

[3] Petersson A, Thiringer T, Harnefors L, Petru T. Modeling and experimental verification of grid interaction of a DFIG wind turbine, IEEE Trans. Energy Convers 2005; 20 (4):878-886.

[4] Bianchi F, Mantz R, Christiansen C. Power regulation in pitchcontrolled variable-speed \{WECS $\}$ above rated wind speed. Renew Energy 2004; 29:1911-22.

[5] Boutoubat M, Mokrani L, Machmoum M. Control of a wind energy conversion system equipped by a $\{\mathrm{DFIG}\}$ for active power generation and power quality improvement. Renew Energy 2013; 50:378-86.

[6] Abad G. Doubly fed induction machine modeling and control for wind energy generation applications, IEEE Press series on power engineering. Oxford: Wiley-Blackwell Pub.; 2011.

[7] ] Muyeen SM, Al-Durra A, Tamura J. Variable speed wind turbine generator system with current controlled voltage source inverter. Energy Convers and Management 2011; 52:2688-94.

[8] Gaillard A, Poure P, Saadate S, Machmoum M. Variable speed \{DFIG\} wind energy system for power generation and harmonic current mitigation. Renew Energy 2009; 34: 1545-53.

[9] Tamaarat A, Benakcha A. Performance of PI controller for control of active and reactive power in DFIG operating in a grid-connected variable speed wind energy conversion system. Front. Energy; 2014. pp.1-8.

[10] Pati S and Samantray S. Decoupled control of active and reactive power in a DFIG based wind energy conversion system with conventional P-I controllers. In: 2014 International Conference on Circuits, Power and Computing Technologies (ICCPCT-2014), Nagercoil, India: IEEE; 2014. p. 898-903.

[11] Ademi S, Jovanovic' M. Theoretical and Experimental Evaluation of Vector Control for Doubly-Fed Reluctance Generators. In: 2014 International Conference on Electrical Machines (ICEM), 2nd - 5th September 2014, Berlin, Germany: IEEE; 2014. p. 936-942.

[12] Pena R, Cardenas R, Escobar E, Clare J, Wheeler P. Control strategy for a Doubly-Fed Induction Generator feeding an unbalanced grid or standalone load. Electric Power Systems Research 2009; 79(2):355-364.

[13] Amrane F, Chaiba A, Babes BE, Mekhilef S. Design and 
implementation of high performance field oriented control for gridconnected doubly fed induction generator via hysteresis rotor current controller. Rev. Roum. Sci. Techn.- Électrotechn. et Énerg 2016; 61(4):319-324.

[14] Yao G, Chen J, Zhou L, Wang X, Huajun YU. Experimental Research of DFIG Based on Wind Energy Conversation System. In: 16th International Power Electronics and Motion Control Conference and Exposition, Antalya, Turkey: IEEE; 2014. p. 426-431.

[15] Melcio R, Mendes V, Catalo J. Comparative study of power converter topologies and control strategies for the harmonic performance of variable-speed wind turbine generator systems. Energy 2011; 36:520-9.

[16] Martinez MI, Tapia G, Susperregui A. Sliding Mode Control for DFIG Rotor and Grid Side Converters under Unbalanced and Harmonically Distorted Grid Voltage. IEEE Transactions on Energy Conversation 2012; 27 (2):328-339.

[17] Costa JP, Pinheiro H, Degner T, Arnold G. Robust controller for DFIGs of grid-connected wind turbines. IEEE Trans Ind Electron 2011; 58(9):4023-38.

[18] Bounadja E, Djahbar A, Boudjema Z. Variable structure control of a doubly fed induction generator for wind energy conversion systems. The International Conference on Technologies and Materials for Renewable Energy, Environment and Sustainability, TMREES14. Energy Procedia 2014; 50:999 - 1007

[19] Hamane B, Benghanem M, Bouzid A, Belabbes A, Bouhamida M, Draoui A. Control for Variable Speed Wind Turbine Driving a Doubly Fed Induction Generator using Fuzzy-PI Control. Energy Procedia 2012; 18:476-485.

[20] Dida A, Ben Attous D. Doubly-fed induction generator drive based WECS using fuzzy logic controller. Front. Energy 2015, 9(3): 272-281.

[21] Djeriri Y, Meroufel A, Allam M. Artificial neural network-based robust tracking control for doubly fed induction generator used in wind energy conversion systems. Journal of Advanced Research in Science and Technology 2015, 2(1):173-181.

[22] Bedoud K, Ali-rachedi M, Bahi T, Lakel R, Grid A. Robust Control of Doubly Fed Induction Generator for Wind Turbine under SubSynchronous Operation Mode. Energy Procedia 2015; 74:886-899.

[23] Dulau M, Gligor A, Dulau TM. Fractional Order Controllers versus Integer Order Controller. $10^{\text {th }}$ International Conference Interdisciplinary In Engineering, INTER -ENG 2016. Procedia Engineering 2017; 181.p.538-545.

[24] Podlubny I. Fractional-order systems and PID controllers. IEEE Transactions on Automatic Control 1999; 44(1): 208-214.

[25] Monje CA, Chen YQ, Vinagre BM, Xue D, Feliu V. Fractional-order Systems and Controls- Fundamentals and Applications. Advances in Industrial Control, springer, 2010.

[26] Podlubny I, Petras I, Skovranek T, Terpak J. Toolboxes and programs for fractional-order system identification, modeling, simulation, and control. In: 2016 17th International Carpathian Control Conference (ICCC). Tatranska Lomnica, Slovakia: IEEE; 2016.p. 608-12.

[27] Tavazoel MS. From Traditional to Fractional PI Control: A Key for Generalization. IEEE IndustrIal Electronics 2012; 6(3):41-51.

[28] Ramasamya M, Sundaramoorthy S. PID controller tuning for desired closed-loop responses for SISO systems using impulse response. Computers and Chemical Engineering 2008; 32:1773-1788.

[29] Charef A. Modeling and Analog Realization of the Fundamental Linear Fractional Order Differential Equation. Springer 2006, Nonlinear Dynamics 2006; 46: 195-210.

[30] Barbosa RS, Machado JAT, Frrreira IM. Tuning of PID Controllers Based on Bode's Ideal Transfer Function. Nonlinear Dynamics 2004; 38:305-321.

[31] Calderon AJ, Vinagre BM, Feliu V. Fractional order control strategies for power electronic buck converters. Signal Processing 2006; 86:28032819.

[32] Petras I. Fractional- Order Feedback Control of a DC Motor. Journal of Electrical Engineering 2009; 3:117-128.

[33] Narang A, Shah SL, Chen T. Tuning of fractional PI controllers for fractional order system models with and without time delays. In: Proceedings of the 2010 American Control Conference, Baltimore, MD, USA: IEEE; 2010.p. 6674-79.

[34] Lino P, Maione G, Stasi S, Padula F, Visioli A. Synthesis of Fractionalorder PI Controllers and Fractional-order Filters for Industrial Electrical Drives. IEEE/CAA Journal of automatic sinica 2017; 4(1): 58-69.

[35] Ganjefar S, Mohammadi A. Variable speed wind turbines with maximum power extraction using singular perturbation theory. Energy 2016; 106:510-519.
[36] Phan DC, Yamamoto S. Maximum Energy Output of a DFIG Wind Turbine Using an Improved MPPT-Curve Method. Energies 2015; 8:11718-11736

[37] Taraft S, Rekioua D, Aouzellag D, Bacha S. A proposed strategy for power optimization of a wind energy conversion system connected to the grid. Energy Conversion and Management 2015; 101:489-502.

[38] Kerrouche K, Mezouar A, Belgacem KH. Decoupled Control of Doubly Fed Induction Generator by Vector Control for Wind Energy Conversion System. Overview of renewable energies exploitation in Algeria. Energy Procedia 2013; 42:239-248.

[39] Akel F, Ghennam T, Berkouk EM, Laour M. An improved sensorless decoupled power control scheme of grid connected variable speed wind turbine generator. Energy Conversion and Management 2014; 78:584594

[40] Kesraouia M, Chaib A, Meziane A, Boulezaz A. Using a DFIG based wind turbine for grid current harmonics filtering. Energy Conversion and Management 2014; 78 :968-975.

[41] Kaloi GS, Wang J, Baloch MH. Active and reactive power control of the doubly fed induction generator based on wind energy conversion system. Energy Reports 2016; 2:194-200.

[42] Dulau M, Gligor A, Dulau TM. Fractional Order Controllers versus Integer Order Controller. $10^{\text {th }}$ International Conference Interdisciplinary In Engineering, INTER -ENG 2016. Procedia Engineering 2017; 181:538-545.

[43] Petras I. Fractional-Order Nonlinear Systems- Modeling, Analysis and Simulation. Nonlinear physical science, Higher Education Press, Beijing and Springer-Verlag Berlin Heidelberg 2011.

[44] Samir L, Bensafia Y. Indirect fractional order pole assignment based adaptive control. Engineering Science and Technology 2015; 19(1): 518530.

[45] Charef A, Sun HH, Tsao YY, Onaral B. Fractal System as Represented by Singularity Function. IEEE Transactions on automatic control 1992; 37(9): 1465-1470.

[46] Mahvash H, Taher SA, Rahimi M. A new approach for power quality improvement of DFIG based wind farms connected to weak utility grid. Ain Shams Engineering Journal 2017; 8(3):415-430.

\section{Creative Commons Attribution License 4.0 (Attribution 4.0 International, CC BY 4.0)}

This article is published under the terms of the Creative Commons Attribution License 4.0

https://creativecommons.org/licenses/by/4.0/deed.en_US 